\title{
The dehydration stress of couch grass is associated with its lipid metabolism, the induction of transporters and the re- programming of development coordinated by $A B A$
}

\author{
Anna Janská1, Pavel Svoboda ${ }^{2,3^{*}}$, Vojtěch Spiwok ${ }^{3}$, Ladislav Kučera² and Jaroslava Ovesná ${ }^{2}$
}

\begin{abstract}
Background: The wild relatives of crop species represent a potentially valuable source of novel genetic variation, particularly in the context of improving the crop's level of tolerance to abiotic stress. The mechanistic basis of these tolerances remains largely unexplored. Here, the focus was to characterize the transcriptomic response of the nodes (meristematic tissue) of couch grass (a relative of barley) to dehydration stress, and to compare it to that of the barley crown formed by both a drought tolerant and a drought sensitive barley cultivar.

Results: Many of the genes up-regulated in the nodes by the stress were homologs of genes known to be mediated by abscisic acid during the response to drought, or were linked to either development or lipid metabolism. Transporters also featured prominently, as did genes acting on root architecture. The resilience of the couch grass node arise from both their capacity to develop an altered, more effective root architecture, but also from their formation of a lipid barrier on their outer surface and their ability to modify both their lipid metabolism and transporter activity when challenged by dehydration stress.

Conclusions: Our analysis revealed the nature of dehydration stress response in couch grass. We suggested the tolerance is associated with lipid metabolism, the induction of transporters and the re-programming of development coordinated by ABA. We also proved the applicability of barley microarray for couch grass stress-response analysis.
\end{abstract}

Keywords: Couch grass, Rhizome, Barley, Crown, Drought, Microarray, Dehydration stress

\section{Background}

Drought stress represents the commonest agent of abiotic stress in plants. As a consequence of the changing climate, it is likely to become an even more regular feature in regions, which currently experience it only occasionally [1-3]. The implication is that crop improvement programs will need to increasingly prioritize drought tolerance as a breeding goal, while at the same time retaining the potential to yield well in the absence of the stress.

\footnotetext{
*Correspondence: pavel.svoboda@vurv.cz

2Division of Crop Genetics and Breeding, Crop Research Institute, Prague, Czech Republic

${ }^{3}$ Factulty of Food and Biochemical Technology, University of Chemistry and Technology, Prague, Czech Republic

Full list of author information is available at the end of the article
}

While it may be possible to achieve these breeding goals empirically, more rapid progress should be possible if the mechanistic basis of drought tolerance were better understood. Much research effort continues to be expended in this direction in the major crop species, as well as in their model species. However, despite the recognition that many crop wild relatives are more resilient than the crop species themselves, little attention has been paid to exploring tolerance mechanisms in these species. A particular example is the small grain cereal relative couch grass (CG) (Elymus repens, syn. Elytrigium repens, Agropyron repens and Triticum repens). This perennial, hexaploid Triticeae species (the same tribe to which the three leading small-grained temperate cereals wheat,

(c) The Author(s). 2018 Open Access This article is distributed under the terms of the Creative Commons Attribution 4.0 International License (http://creativecommons.org/licenses/by/4.0/), which permits unrestricted use, distribution, and reproduction in any medium, provided you give appropriate credit to the original author(s) and the source, provide a link to the Creative Commons license, and indicate if changes were made. The Creative Commons Public Domain Dedication waiver (http://creativecommons.org/publicdomain/zero/1.0/) applies to the data made available in this article, unless otherwise stated. 
barley, wheat and rye belong) has been ranked among the three most serious weed species, infesting 37 crops across 65 countries [4]. Its strong competitive ability derives at least in part from its formation of rhizomes, which are highly tolerant of prolonged periods of moisture stress, and readily regenerate into whole plants when moisture becomes available.

The transcriptomic response of a number of plant species to drought or dehydration stress has been explored in depth in recent years, thanks to the development of genomic tools such as the DNA microarray. As one of the three sub-genomes of CG $(\mathrm{H})$ is closely related to the barley genome [5-7], the assumption is that tools developed for barley should be informative in CG. The success of this heterologous approach has already been demonstrated in the genus Sorghum, where microarrays developed for $S$. bicolor have been used to investigate the transcriptome of its perennial, rhizomatous wild relative S. propinquum [8]. Similarly, the Arabidopsis thaliana microarray has been exploited to carry out transcriptomic analyses of a range of close and even rather distant relatives [9-11], while a soybean microarray has been shown to be functional in common bean [12] and a tomato microarray in potato [13], pepper and eggplant [14] and strawberry [15].

Here we tested the hypothesis that the dehydration stress response of barley crown and the node of its wild extremely tolerant relative (couch grass) is different. We discuss mechanisms of acclimation to dehydration which play a crucial role in couch grass node, plant part critical for whole plant survival, similar to barley crown. We suggest the critical role of lipid metabolism, the induction of transporters and the re-programming of development coordinated by ABA (abscisic acid) in the dehydration stress response of couch grass leading to drought stress tolerance. These results could be interesting for barley breeding programs to develop drought tolerant genotypes, enable novel insight into adaptation of extremely tolerant plant species and demonstrate the applicability of barley microarray for couch grass transcriptome analysis. The dehydration stress responses of two barley cultivars contrasting with respect to drought tolerance have been described in our previous study [16].

\section{Results}

Relative water content, electrolyte leakage and resprouting

Before the stress was applied, the CG rhizome segments had an relative water content (RWC) of 59.6\% (Fig. 1a), equivalent to a water content of $1.48 \mathrm{~g}$ per g dry matter (DM) (Fig. 1b). After exposure to the mild dehydration treatment $\left(2 \mathrm{~h}\right.$ at $28{ }^{\circ} \mathrm{C}$ ), the RWC declined to $44.7 \%$ (1. $11 \mathrm{~g}$ per $\mathrm{g} \mathrm{DM})$; the medium treatment $(4.5 \mathrm{~h})$ further decreased RWC to $31.8 \%$ (0.79 g per g DM), and the severe treatment $(8 \mathrm{~h})$ to $20.5 \%(0.51 \mathrm{~g}$ per g DM). After $22 \mathrm{~h}$, the RWC reached $3.2 \%$ (0.08 g per g DM). After
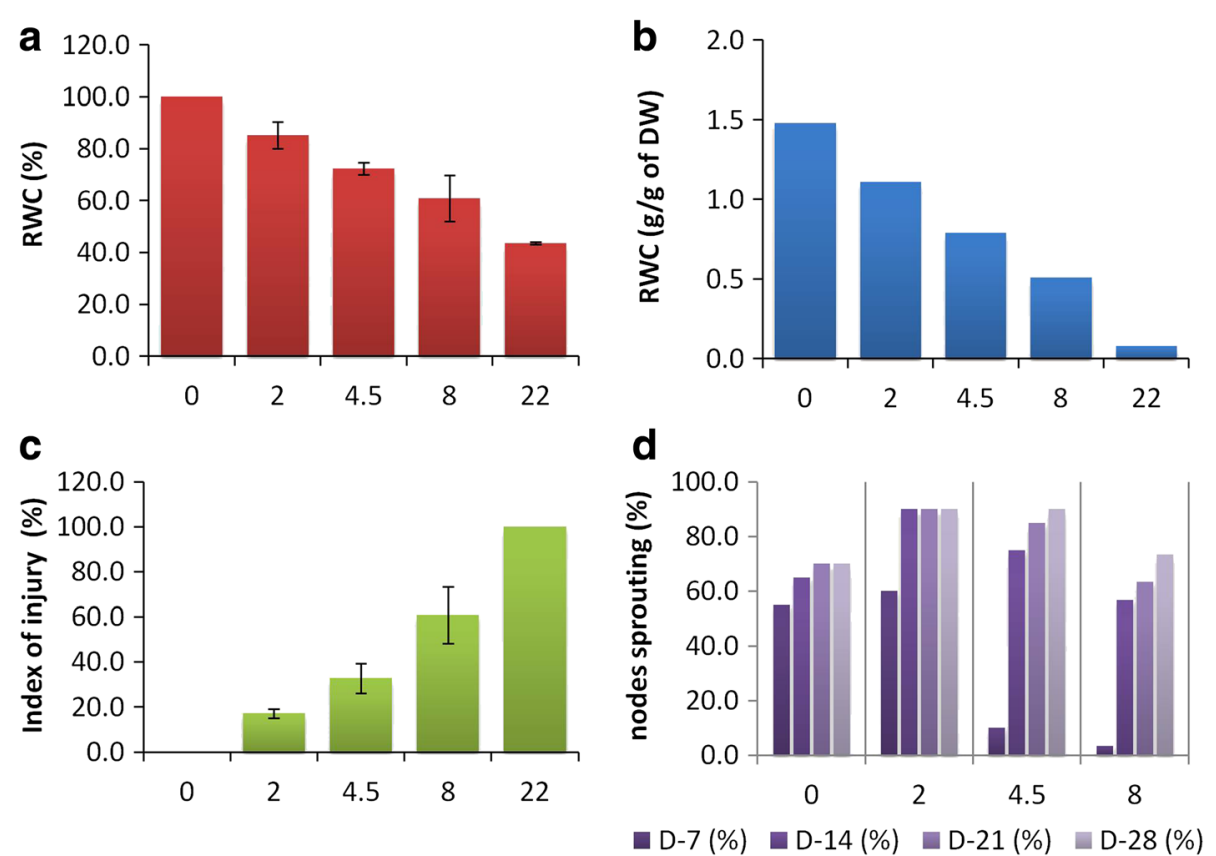

Fig. 1 The physiological status of the dehydration-stressed rhizomes. a, b Water contents expressed as (a) a relative water content in \% and (b) $\mathrm{g}$ per g DM. c Electrolyte leakage expressed in the form of an injury index. $\mathbf{d}$ The proportion of rhizomes able to regenerate new shoots when rewatered. The $x$ axis depicts the duration of stress in h; D-7,D-14,D-22, D-28 represents the number of days after replanting 
the latter treatment, the rhizome segments were no longer viable. The response of $I_{t}$ to the treatments is shown in Fig. 1c. The range was from $0 \%$ (non-treated control) to $100 \%$ (dead). After the mild stress, this index rose to $17.2 \%$, after the medium stress to $32.8 \%$ and after the severe stress to $60.9 \%$. When the rhizome segments were replanted, by seven days, $55 \%$ of the non-treated ones had sprouted, rising to $70 \%$ after 21 days; the proportion did not rise further (Fig. 1d). For the treated segments, the proportions which re-sprouted after seven days were $60 \%$ (mild), 10\% (medium) and 3\% (severe). The effect of stress was of short duration, as by 28 days, $90 \%$ of the segments exposed to the mild and medium stress levels were able to re-sprout, while the re-sprouting proportion of the severely stressed segments was $73 \%$.

\section{Global comparison of transcription profiles and data quality}

Microarray raw data analysis using MAS 5.0 algorithm revealed that nearly half (10076) of all features on barley1 GeneChip (22840) were called as present on all biological replicates of at least one sample once hybridized with CG RNA (Fig. 2). In addition, majority of those features (6496) were called present on all arrays (Fig. 2). These probe sets were considered to detect barley homologs within the CG genome involved in stress response and confirmed the applicability of barley1 GeneChip for the CG stress response analysis.

\section{The identification of differentially transcribed genes (DTGs)}

Through use of the LIMMA algorithm, 1309 probe sets were identified as being significantly altered between treated and non-treated samples (Fig. 3). Of these, 536 (40.9\%) related to the contrast non-treated vs mildly stressed rhizome segments, $821(62.7 \%)$ to the contrast with the medium stress level and 1197 (91.4\%) with the severe stress level. About $40 \%$ of the DTGs were identified at only a single stress level (67 at the mild level, 23 at the medium level and 414 at the severe level), while $~ 34 \%$ were detect at all three levels, and the remaining were detected at two of the three levels ( 22 shared by the mild and medium levels, 336 by the medium and severe levels and 7 to the mild and severe levels). Of the 440 DTGs associated with all three stress levels, 283 were up-regulated by the stress and 157 down-regulated. Among the former, 162 showed a progressive enhancement in transcription as the stress level was increased (Table 1). The PCA (principal component analysis) applied to the set of DTGs is illustrated in Fig. 4. The first two components explained, respectively, $84.0 \%$ and $10.5 \%$ of the total variance. Variation between biological replicates represented only a small proportion of the total, confirming the datasets quality. There were significant differences not only between the non-treated and treated rhizome segments, but also between treatments.

\section{Functional analysis of the set of DTGs}

The DTGs associated with all three stress levels were grouped into ten clusters on the basis of their response to an increasing level of stress (Fig. 5; Additional file 1: Table S3, Additional file 2: Table S4, Additional file 3: Table S5, Additional file 4: Table S6, Additional file 5: Table S7, Additional file 6: Table S8, Additional file 7: Table S9, Additional file 8: Table S10, Additional file 9: Table S11, and Additional file 10: Table S12).

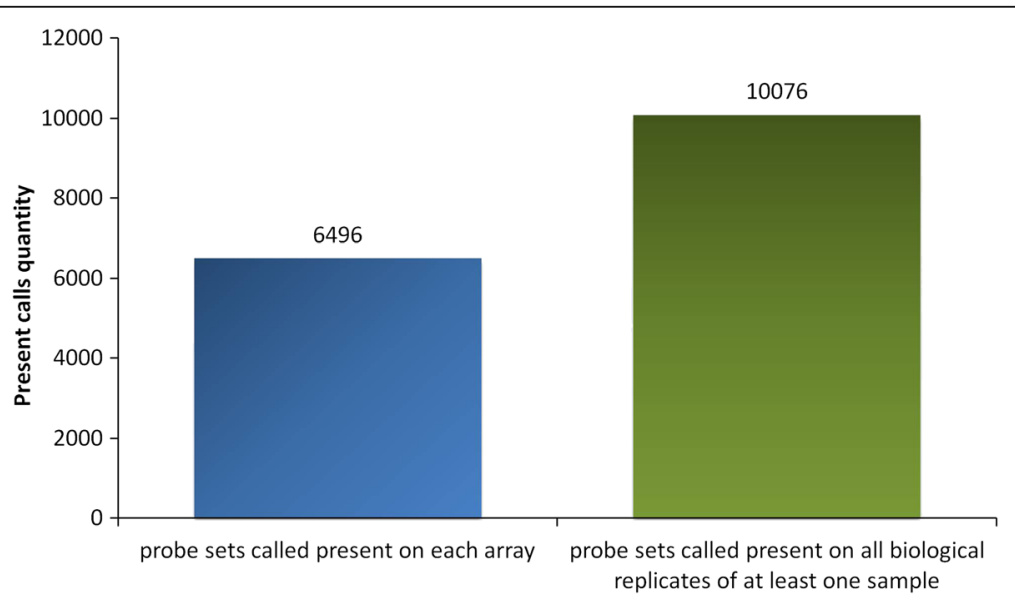

Fig. 2 Statistics relating to "present calls" when CG transcripts were hybridized to the barley microarray. "Present calls" corresponds to probe sets outputting a signal intensity significantly higher for perfect matches (100\% sequence complementarity to the reference sequence) than for mismatches ( $\mathrm{MM}$ - differ from the perfect match probes by a single base substitution at the centre base position, disturbing the binding of the target gene transcript. MM serve as a control for cross-hybridization). The blue bar represents the numbers of probe sets called as present on each array, while the green bar displays the number of probe sets called as present on all biological replicates of at least one sample. The numbers on the $y$ axis depict the quantity of probe sets 


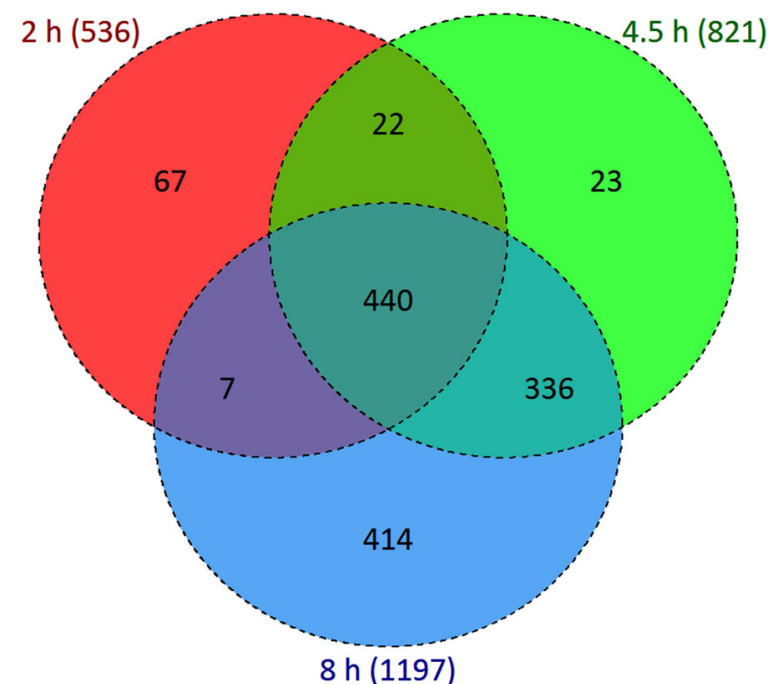

Fig. 3 The specificity and commonality of DTGs in the dehydration treated CG rhizomes

Cluster \#1 (162 DTGs; Table 1; Additional file 1: Table S3) was formed by genes up-regulated gradually by exposure to the stress treatment, and whose products are likely relevant for either the response to osmotic stress and/or are promoted by abscisic acid (ABA). About a quarter of the products of these genes (43 DTGs) could be associated with catalytic activity: for example, 13 are oxidoreductases, and 42 are expressed in membrane-bounded organelles. One of the most strongly stimulated genes encodes 9-cis-epoxycarotenoid dioxygenase (NCED; AT1G78390.1), an enzyme which catalyzes the first step of ABA synthesis; other stress up-regulated ABA-inducible genes included several encoding so-called "late embryogenesis abundant" (LEA) proteins which, under conditions of osmotic stress, inhibit the loss of activity of a number of enzymes. Examples of these are several members encoding $\mathrm{Y}_{\mathrm{n}} \mathrm{Sk}_{\mathrm{m}}$ dehydrins (Table 2), documented to accumulate in barley plants in response to dehydration [17]. The genes encoding HVA1 (AT3G15670.1), WSI18 (AT3G15670.1) and the LEA14-A protein (AT1G 01470.1) were also up-regulated by the stress. Several of the Cluster \#1 DTGs encoded proteins/enzymes involved in carbohydrate metabolism, namely UDP-glucose 4-epimerase (AT4G23920.1), a putative trehalose-6-phosphate phosphatase (AT4G12430.1), galactinol synthase (AT1G09350.1) and a putative raffinose synthase (AT5G40390.1). A gene encoding pyrroline-5-carboxylate synthetase (AT2G39800.1) also belonged to this cluster, as did genes encoding proteins involved in stress signal transduction such as protein phosphatase 2C (AT1G72770.3, AT4G28400.1, AT4G28400.1, AT4G31750.1, AT1G72770.3), phosphatidylinositol-3phosphate 5-kinase (PI3PK; AT1G34260.1), MAP kinase (AT1G10210.2), Ser/Thr protein kinase (AT5G18610.1, AT
5G56460.1) and a putative calcium-binding protein (AT4 G26470.1, AT4G38810.2).

Clusters \#3 (81 DTGs; Additional file 3: Table S5), \#5 (35 DTGs; Additional file 5: Table S7) and \#7 (three DTGs; Additional file 7: Table S9) included genes responding positively after the mild dehydration stress treatment and remained either strongly transcribed, or as those grouped into Cluster \#5 - showed a peak level of transcription in the medium dehydration stress treatment. Products of these genes are involved in signaling (seven DTGs) or the response to ABA treatment (six DTGs) and/or the imposition of osmotic (five DTGs) or low temperature (six DTGs) stress; five of these genes are known to encode transporters. The two genes grouped into Cluster \#10 (Additional file 10: Table S12) were both rapidly up-regulated by moisture stress. One of the two genes is a typical "stress response" gene, encoding an LTI (or Blt 101.1, low temperature induced) protein (AT2G38905.1) and the other encoded an unknown protein (HS07G10u_s_at).

Cluster \#2 (86 DTGs; Additional file 2: Table S4) groups genes down-regulated gradually during the exposure to stress: their products are associated with carbohydrate metabolism (ten DTGs), alcohol catabolism (six DTGs), catalysis (32 DTGs) and transferase (14 DTGs). The products of 20 of these genes are thought to localize to the cytoplasm.

Clusters \#4 (24 DTGs; Additional file 4: Table S6), \#6 (18 DTGs; Additional file 6: Table S8), \#8 (24 DTGs; Additional file 8: Table S10) and \#9 (five DTGs; Additional file 9: Table S11) harbor genes, which were down-regulated by the mild dehydration stress treatment and remained down-regulated. A number of these genes encoded either proteins localized within an organelle or which possessed catalytic activity.

In all, there were 67 DTGs exclusively induced by the mild dehydration stress treatment (half up- and half down-regulated). Those which were up-regulated encoded products associated with cross membrane transport, specifically of citrate (putative transmembrane protein AT1G02260.1), amino acids and water (NOD26like intrinsic protein 1;2, AT4G18910.1; $\delta$ tonoplast intrinsic protein, AT3G16240.1; plasma membrane intrinsic protein 2A (PIP2A), AT3G53420.2; amino acid transporter family protein, AT3G56200.1). Others encoded products, some of which localized to the cell wall, including extensin (AT4G13340.1), expansin (AT 1G69530.2) and glycosyl hydrolase (AT1G78060.1); others were implicated in the abiotic stress response (ascorbate peroxidase (AT1G07890.8)) and still others in ABA signaling (ABRE binding factor 4 (AT3G19290.1); protein phosphatase 2CA (AT3G11410.1)). The group of down-regulated genes included three encoding small heat shock proteins (AT5G59720.1; AT4G27670.1; 
Table 1 Selected DTGs whose transcription was enhanced by increasing the severity of the dehydration treatment

\begin{tabular}{|c|c|c|c|c|c|}
\hline \multirow[t]{2}{*}{$\overline{\mathrm{ID}^{\mathrm{a}}}$} & \multicolumn{3}{|c|}{$\log 2 \mathrm{FC}^{\mathrm{b}}$} & \multirow[t]{2}{*}{ Affymetrix annotation $^{d}$} & \multirow[t]{2}{*}{$A G l^{e}$} \\
\hline & $\overline{2^{c}}$ & $4.5^{c}$ & $8^{c}$ & & \\
\hline HT11N18r_s_at & 5.19 & 5.60 & 5.77 & 9-cis-epoxycarotenoid dioxygenase & AT1G78390.1 \\
\hline Contig1718_s_at & 4.17 & 5.16 & 5.18 & dehydrin 9 & AT3G50980.1 \\
\hline Contig2406_at & 3.75 & 4.88 & 5.16 & ABA-inducible protein WRAB1 & AT3G15670.1 \\
\hline Contig7672_at & 3.92 & 4.78 & 4.85 & protein phosphatase $2 \mathrm{C}$ & AT4G31750.1 \\
\hline Contig8184_at & 3.97 & 4.50 & 4.50 & WSI18 protein & AT3G15670.1 \\
\hline HV06O23u_at & 3.60 & 3.95 & 3.98 & mRNA cleavage factor subunit & AT4G29820.1 \\
\hline Contig13161_at & 2.88 & 3.73 & 3.94 & protein phosphatase $2 \mathrm{C}$-like protein & AT1G72770.3 \\
\hline Contig1713_s_at & 2.78 & 3.75 & 3.80 & dehydrin 4 & AT5G66400.1 \\
\hline Contig14720_s_at & 1.87 & 3.14 & 3.74 & putative phosphoinositide kinase & AT1G34260.1 \\
\hline HV10J12u_s_at & 2.70 & 3.45 & 3.71 & actin depolymerization factor-like & AT5G59880.1 \\
\hline Contig14870_at & 3.46 & 3.65 & 3.71 & putative trehalose-6-phosphate & AT4G12430.1 \\
\hline Contig2407_s_at & 2.42 & 3.43 & 3.70 & ABA-inducible protein $\mathrm{PHV} A 1$ & AT3G15670.1 \\
\hline Contig1708_s_at & 2.07 & 3.37 & 3.60 & dehydrin 6 & AT4G01985.1 \\
\hline Contig1701_s_at & 1.97 & 3.10 & 3.47 & dehydrin 2 & AT3G50980.1 \\
\hline Contig1724_s_at & 2.66 & 3.11 & 3.40 & dehydrin 3 & AT5G66400.1 \\
\hline Contig2405_at & 2.33 & 3.22 & 3.34 & group 3 LEA protein & AT3G15670.1 \\
\hline Contig10934_at & 2.56 & 3.09 & 3.32 & Putative abscisic acid-induced protein & AT3G22490.1 \\
\hline Contig8905_at & 1.56 & 3.02 & 3.31 & xylanase inhibitor protein I & \\
\hline rbaal10h14_at & 1.07 & 2.27 & 3.30 & abscisic acid-induced protein & \\
\hline Contig3807_at & 1.78 & 2.85 & 3.26 & putative nifU-like protein & AT4G22220.1 \\
\hline Contig8220_at & 2.49 & 2.97 & 3.17 & late embryogenesis abundant protein & AT4G21510.1 \\
\hline HVSMEm0008B04r2_s_at & 2.28 & 3.06 & 3.14 & UDP-glucose 4-epimerase & AT4G23920.1 \\
\hline Contig5724_at & 1.62 & 2.50 & 2.96 & 4-hydroxyphenylpyruvate dioxygenase & AT1G06570.1 \\
\hline Contig3810_at & 1.75 & 2.89 & 2.93 & WSI76 protein/Galactinol synthase & AT1G09350.1 \\
\hline Contig4942_at & 1.46 & 2.46 & 2.89 & ATP-dependent Clp protease & AT5G51070.1 \\
\hline Contig4955_s_at & 2.44 & 2.82 & 2.87 & putative sugar-starvation induced & AT2G32150.1 \\
\hline Contig26196_at & 1.89 & 2.75 & 2.86 & putative raffinose synthase & \\
\hline EBro08_SQ007_B12_s_at & 1.32 & 2.02 & 2.77 & ABA-inducible protein WRAB1 & AT3G15670.1 \\
\hline Contig6110_at & 1.15 & 2.36 & 2.67 & $\mathrm{Ca} 2+-$ dependent lipid-binding protein & \\
\hline Contig4760_s_at & 2.10 & 2.62 & 2.63 & putative late embryogenesis abundant & AT1G01470.1 \\
\hline Contig2924_s_at & 1.18 & 2.28 & 2.61 & aldehyde dehydrogenase homolog Dha1 & AT1G54100.2 \\
\hline Contig10022_at & 1.33 & 2.11 & 2.61 & putative glycine-rich cell wall protein & AT5G53870.1 \\
\hline HF18A22r_s_at & 1.54 & 2.34 & 2.61 & Formate dehydrogenase, mitochondrial & AT5G14780.1 \\
\hline
\end{tabular}

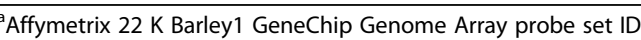

${ }^{\mathrm{b}} \mathrm{Log}_{2}$ transformed fold change of treated samples against controls

cduration of stress (h)

dMicroarray manufacturer's annotation of individual IDs

${ }^{\mathrm{e}} A$. thaliana locus identifier corresponding to individual IDs

AT3G46230.1) and one a fatty acid desaturase (AT5G05580.1). Of the 23 genes exclusively induced by the medium stress treatment, the up-regulated group included genes encoding dehydrin (AT5G66400.1), chitinase (AT2G43590.1), glutamine-dependent asparagine synthase 1 (AT3G47340.1) and oxidative stress 3 (AT5G56550.1), while the down-regulated group included genes encoding 3-ketoacyl-CoA synthase 20 (AT5G43760.1) and peroxidase 21 (AT2G37130.2). A much larger group was formed by the 414 genes exclusively induced by the severe dehydration stress treatment. Of these, 189 were up- and 225 down-regulated. Many (53) of the up-regulated group encoded proteins having catalytic activity, nine are involved in active 


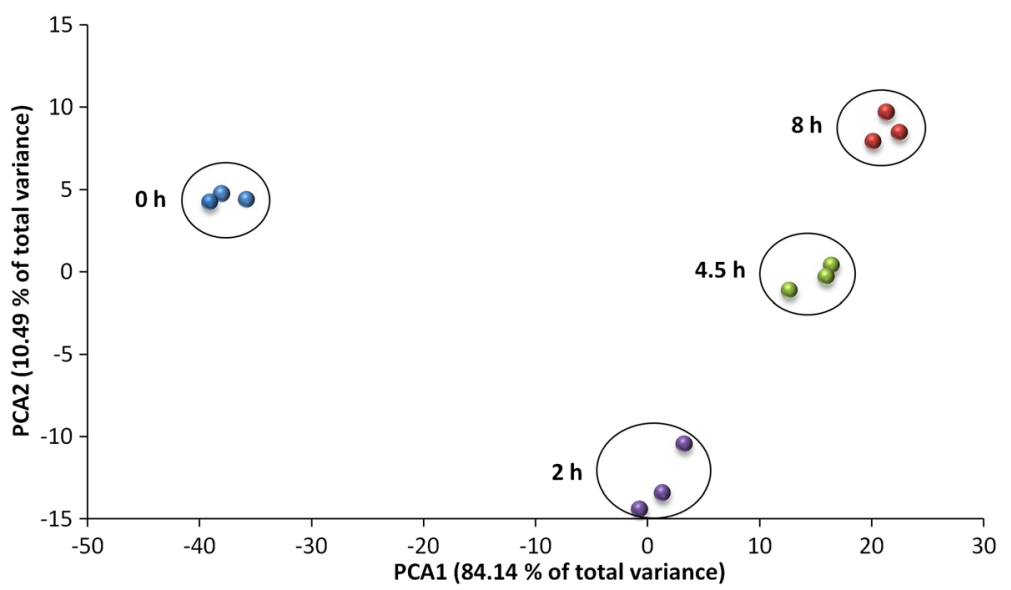

Fig. 4 PCA applied to the set of all DTGs. The $x$ and $y$ axes correspond to the two main components. The data in parentheses indicate the contribution of the given component to the overall variance. Circles represent individual samples, while points within each circle represent the biological replicates. Blue points on the left side correspond to non-treated samples, while the purple, green and red points on the right side represent the three simulated dehydration treatments

transmembrane transport, 44 localize to the cytoplasm, 43 are expressed within an organelle and seven within the vacuole. Some of these genes encode enzymes involved in the synthesis of phenolic compounds, such as cinnamyl alcohol dehydrogenase (AT4G37980.1), arogenate dehydratase 4 (AT3G44720.1), fumarylacetoacetate hydrolase-like protein (AT1G12050.1) and cinnamate-4-hydroxylase (AT2G30490.1), and some in lipid metabolism, e.g. phospholipase D (AT3G16785.1), esterase (AT5G41120.1), long-chain-fatty acid CoA ligase family protein (AT2G04350.2). Among the downregulated group, there was an over-representation of genes encoding products associated with anatomical structure development (19 DTGs), transport (17 DTGs, of which 13 have substrate-specific transporter activity) and nitrogen metabolism (29 DTGs). There were also a number of genes the products of which participate in translation (19 DTGs), especially the structural constituents of the ribosome (16 DTGs).

\section{The comparative response of CG and barley}

The transcriptomic dehydration response of the crown of the two contrasting (with respect to drought tolerance) barley cultivars cv. Amulet (drought sensitive) and cv. Tadmor (drought tolerant) has been documented in our previous study [16]. Among the 4132 DTGs identified in barley, 290 were shared between CG and both barley cultivars, 55 between CG and cv. Tadmor, and 154 between CG and cv. Amulet. There were 810 DTGs, which were specific to CG (Fig. 6; Additional file 11: Table S13). Among the 290 common DTGs, there were 21 genes encoding transporters or proteins associated with transport and localization: of these, six are lipid transfer proteins. A second group of over-represented genes encoding proteins is involved in ABA signaling (12 DTGs), the response to moisture deficiency (ten DTGs) or oxidative stress (seven DTGs): most of these were up-regulated by the stress. Another shared upregulated gene encoded spermidine synthase 3 (AT5G53120.5), an enzyme involved in polyamine synthesis. Some of the DTGs in this category were down-regulated in barley, but up-regulated in CG or vice versa; examples are genes encoding the transporters PIP aquaporin (PIP2A; AT3G53420.2), vacuolar iron transporter 1.1 (VIT1.1; AT2G01770.1) and a tonoplast intrinsic protein 1;3 (TIP1;3; AT4G01470.1), all of which were down-regulated in both barley cultivars, but upregulated in CG in each of the three drought treatments. A similar behavior was exhibited by a gene encoding a dehydrin (AT1G54410.1), while the opposite behavior (up-regulated in both barley cultivars, but downregulated in CG) was exhibited by a gene encoding an $18 \mathrm{KDa}$ heat shock protein (AT5G59720.1).

The crown of the drought tolerant cv. Tadmor and the node of CG share a similar response to dehydration stress. In both, the set of over-represented DTGs involved those encoding products concerned with post-embryonic development (six genes), anatomical structure development (eight genes) and reproductive structure development (five genes). Among the genes down-regulated in both barley and CG were a gene encoding protein-arginine-N-methyltransferase (PRMT10; AT1G04870.2), associated with the vegetative to reproductive transition; a gene encoding transcriptional factor B3 family protein (NPH4; AT5G20730.2), involved in leaf development and lateral root primordium development; and a homolog of an $A$. 


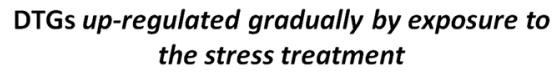

Cluster 1

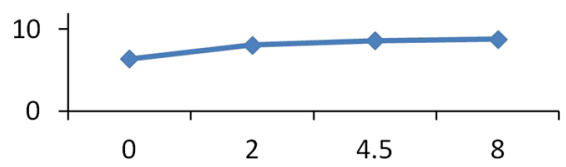

DTGs with increased expression immediately after mild drought and then after exposition to severe drought

Cluster 10

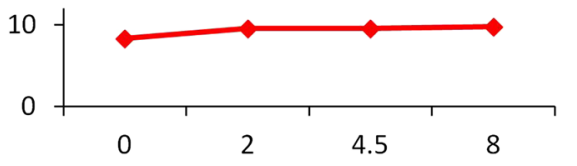

DTGs responding positively after the mild drought stress treatment and remained strongly transcribed

Cluster 3

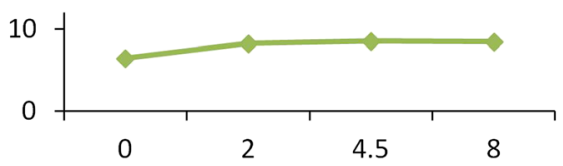

Cluster 7

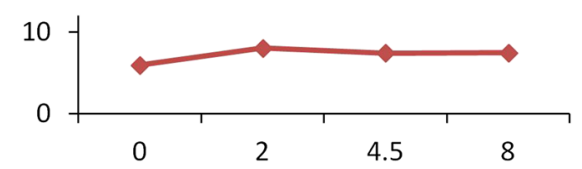

Cluster 5

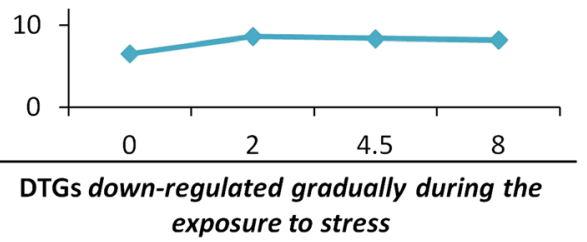

Cluster 2

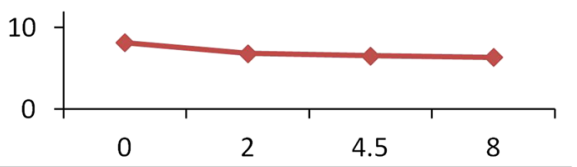

DTGs down-regulated by the mild drought stress treatment and remained down-regulated

Cluster 4

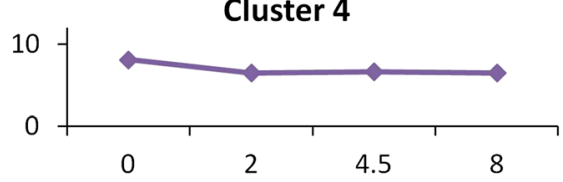

Cluster 8

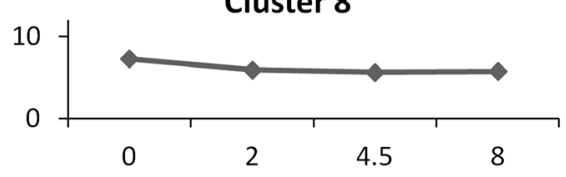

Cluster 6

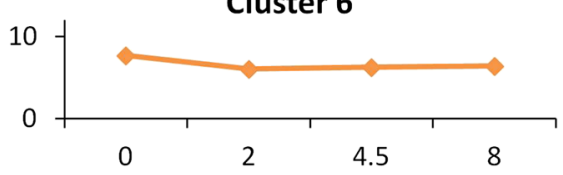

Cluster 9

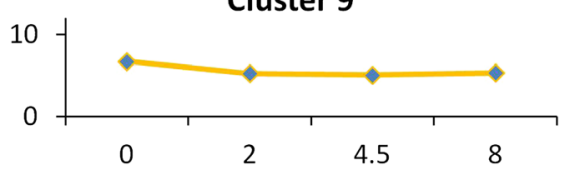

Fig. 5 A cluster analysis of the DTGs common to all tree treatments. The charts display the mean transcript abundance (y axis) for genes grouped into a given cluster

thaliana gene encoding KNOTTED-LIKE HOMEOBOX (AT1G62990.1), involved in xylem development. Among those up-regulated in both cv. Tadmore and CG were a gene encoding oleosin1 (AT4G25140.1), responsible for lipid accumulation. Two genes showed contrasting behavior between cv. Tadmor and CG: these encoded jasmonate-zim domain protein1 (AT1G19180.2), involved in the jasmonate signaling pathway, which was downregulated in cv. Tadmor, but up-regulated in CG; and a gene encoding late elongated hypocotyl (AT1G01060.4), a transcription factor responsive to a broad spectrum of phytohormones and salinity stress [18], which was upregulated in cv. Tadmor and down-regulated in CG.

The most abundant group of CG-specific DTGs included those encoding products involved in carbohydrate metabolism (21 genes), nitrogen metabolism (25 genes) and lipid metabolism (26 genes). There was a particularly pronounced up-regulation of a gene encoding chloroplast $\beta$-amylase (AT4G17090.1), 1-deoxy-D-xylulose 5phosphate reductoisomerase (AT5G62790.1) or glucosyl transferase family 8 (AT1670090.2), while genes encoding phosphofructokinases (AT4G26270.1; AT1G76550.1) were strongly down-regulated. Some genes encoding proteins involved in amino acid metabolism were also upregulated, such as ornithine-delta-aminotransferase (AT5G46180.1) or protein named oxidative stress 3 (AT5656550.1). The significance of lipid metabolism in the drought acclimation process was highlighted by the upregulation of genes encoding a phosphatidyl serine synthase (AT1G15110.1), a possible phosphatidylinositol-3P 5-kinase 
Table 2 DTGs encoding dehydrins

\begin{tabular}{|c|c|c|c|c|c|c|}
\hline \multirow[t]{2}{*}{$\overline{I D^{a}}$} & \multicolumn{3}{|c|}{$\log 2 F C^{b}$} & \multirow{2}{*}{$\begin{array}{l}\text { Affymetrix } \\
\text { annotation }^{\text {d }}\end{array}$} & \multirow{2}{*}{$\begin{array}{l}\text { Structural } \\
\text { type }\end{array}$} & \multirow[t]{2}{*}{$A G I^{f}$} \\
\hline & $\overline{2^{c} \mathrm{Hrs}}$ & $4.5^{c}$ & $8^{c}$ & & & \\
\hline Contig1725_s_at & 0.162 & 0.920 & 1.067 & DHN1 & $Y_{n} S K_{m}$ & AT5G66400.1 \\
\hline Contig1721_at & 0.916 & 1.752 & 2.090 & DHN2 & $Y_{n} S K_{m}$ & AT5G66400.1 \\
\hline Contig1701_s_at & 1.972 & 3.100 & 3.472 & DHN2 & $Y_{n} S K_{m}$ & AT3G50980.1 \\
\hline Contig1724_s_at & 2.662 & 3.115 & 3.402 & DHN3 & $Y_{n} S K_{m}$ & AT5G66400.1 \\
\hline Contig1713_s_at & 2.785 & 3.751 & 3.810 & DHN4 & $Y_{n} S K_{m}$ & AT5G66400.1 \\
\hline Contig1717_s_at & 0.893 & 1.446 & 1.436 & DHN5 & $K_{n}$ & AT3G50970.1 \\
\hline Contig1708_s_at & 2.077 & 3.379 & 3.603 & DHN6 & $Y_{n} S K_{m}$ & AT4G01985.1 \\
\hline Contig1709_at & 1.603 & 2.141 & 2.300 & DHN7 & $Y_{n} S K_{m}$ & AT5G66400.1 \\
\hline Contig2855_at & 1.095 & 1.199 & 0.987 & DHN8 & $S K_{n}$ & AT1G20440.1 \\
\hline Contig1718_s_at & 4.174 & 5.168 & 5.185 & DHN9 & $Y_{n} S K_{m}$ & AT3G50980.1 \\
\hline Dhn10(Morex)_s_at & 1.262 & 1.846 & 2.090 & DHN10 & $Y_{n} S K_{m}$ & AT3G50970.1 \\
\hline Contig10207_s_at & 0.687 & 1.089 & 0.978 & DHN11 & $Y_{n} S K_{m}$ & AT5G66400.1 \\
\hline
\end{tabular}

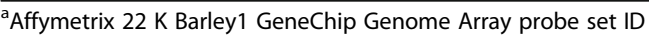

${ }^{b} \log _{2}$ transformed fold change of treated samples against controls

'duration of stress $(\mathrm{h})$

${ }^{d}$ Microarray manufacturer's annotation of individual IDs of individual dehydrins (DHNs)

eStructural type of individual dehydrins

${ }^{\mathrm{f}} A$. thaliana locus identifier corresponding to individual IDs

(or "forms aploid and binucleate cells 1A"; AT1G34260.1), 1-deoxy-D-xylulose 5-phosphate reductoisomerase (AT5 G62790.1), NCED (AT1G78390.1) or squalene synthase (AT4G34640.1). Molecular function of the last one is unknown, but probably is involved in endomembrane homeostasis [19] Other over-represented groups of genes included those encoding proteins involved in the response to osmotic stress ( 35 genes), in the response to ABA (20 genes) and stomatal movement (six genes) as well as with localization (57 genes), developmental processes (62 genes)

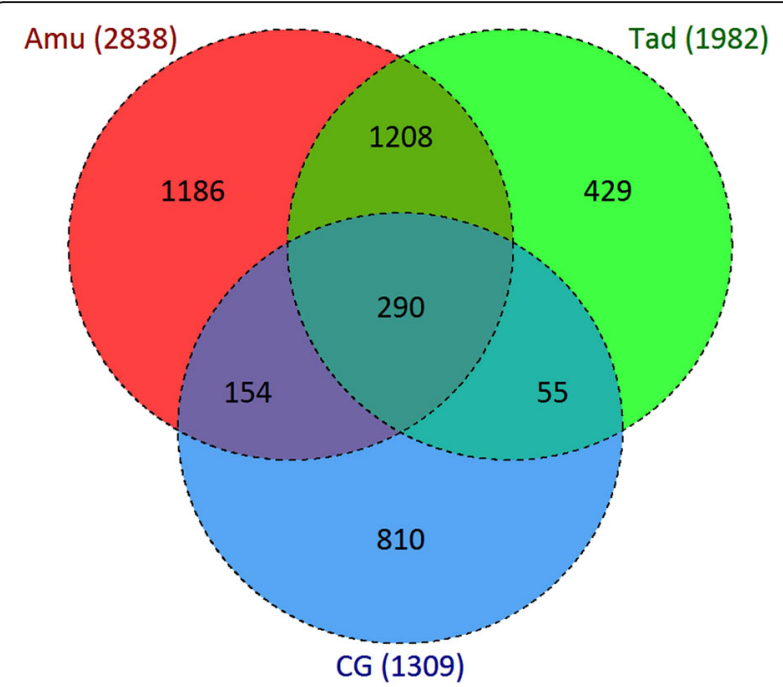

Fig. 6 The specificity and commonality of DTGs in the dehydration treated rhizomes of CG and the crowns of the barley cultivars Tadmor and Amulet and signal transduction (eight genes). The importance of $\mathrm{ABA}$ in the drought stress responses was confirmed not only by the up-regulation of a number of ABA-dependent genes but also by the strong up-regulation of genes involved in ABA synthesis, such as those encoding NCED (AT1G78390.1) and zeaxanthin epoxidase (AT5G67030.1). On the other hand, most of the DTGs encoding products involved in developmental processes were down-regulated: examples were the genes encoding homeobox protein 16 (HB16; AT4G40060.1), RING IV-box superfamily protein (AT3G63530.2) and homeodomain-like superfamily protein (AT1G01060.4); the gene encoding choline/ethanolamine kinase 4 (CEK4; AT2G26830.1) was, however, strongly upregulated. Similar down-regulation was observed in transcription of genes which products are involved in reproductive processes: homeodomain-like superfamily protein (AT1G01060.4), auxin response factor (AT1630330. 2) or bHLH protein (AT4G02590.30). Several genes which products are known to participate in biological regulation were strongly up-regulated, e.g. GIGANTEA protein (AT1 G22770.1), F-box/RNI-like superfamily protein (AT1G2 1410.1), MAPK4 protein (AT1G10210.2) or MYB-like TF (AT5G47390.1). Significant increase in transcription during dehydration in CG rhizomes was observed also in genes which products have catalytic activity, such as haloacid dehalogenase-like hydrolase (AT2G32150.1), pheophytinase (AT5G13800.1), xyloglucanendotransglucosylase/hydrolase 13 (AT5G57540.1), receptor-like protein kinase (AT5G4 0380.1) and nudix hydrolase homolog 8 (AT5G47240.1) as well as in genes with transporter activity such as transmembrane amino acid transporter (AT3G30390.2) or PIP 1;5 
(AT4G23400.1). On the other hand, strong downregulation was observed in transcription of gene encoding phytosylfokine-alpha receptor 2 (AT5G53890.1) known to be involved in controlling cell expansion [20] or alcohol dehydrogenase 1 (AT1G77120.1). Interestingly, transcription of gene enncoding photosystem II subunit QA (AT4G21280.1) as well as transcription of genes coded for proteins with oxidoreductase activity (APS reductase 1, AT4G04610.1; glutathione peroxidase, AT4G11600.1) was up-regulated. Chen et al. [21] suggest that the PSII-LHCII supercomplexes (photosystem II-light harvesting complex II) and LHCII assemblies play an important role in preventing photo-damages to PSII under drought stress.

\section{Validation of the results obtained by microarray analysis via real-time PCR (qRT-PCR)}

Sixteen genes stimulated or inhibited by dehydration within couch grass rhizomes were selected for qRT-PCR analysis (Table 3) and results were compared with those obtained from microarray to validate the robustness of our microarray analysis. Genes were selected according to their impact to the main results from the manuscript and those were: ABA biosynthesis gene NCED (AT1G78390.1), strongly up-regulated by dehydration as well as genes induced by ABA such as dehydrins DHN6 (AT4G01985.1), DHN9 (AT1G09350.1), WRAB1 (AT3G15670.1) or galactinol synthase (WSI76; AT1G09350.1), the key enzyme in raffinose biosynthesis. Induced were also genes associated with lipid metabolism such as PI3PK (AT1G34260.1), glycosylphosphatidylinositol-anchored lipid transfer protein 5 (LTPG5; AT3G22600.1), phospholipid/glycerol acyltransferase (PGLAC; AT1G80950.1) and glycolipid transfer protein (GLTP; AT4G39670.1) or genes encoded transporters, e.g. PIP2A (AT3G53420.2), TIP 1;3 (AT4G01470.1) and ABC transporter (ABC; AT1G15520. 1). On the other hand, down-regulated were genes coded for NPH4 (AT5G20730.2), HB16 (AT4G40060.1) and PRMT10 (AT1G04870.2). However, CEK4 (AT2G26830.1) was up-regulated as found also by microarray analysis. All the genes gave the same transcription trend as in microarray analysis (Fig. 7 and Additional file 12: Table S1), in some cases even more pronounced - see the very strong up-regulation of dehydrins, WRAB1, TIP $1 ; 3$ and NCED as quantified by real time PCR (Fig. 7 and Additional file 12: Table S1).

\section{Discussion}

Plenty of studies have been performed to explore stress adaptational mechanisms of cultivated crop species on a genome scale. However, stress responses of weedy relatives were investigated much less in the past, partially because of the limited number of genomic tools for weedy species. We used Barley1 GeneChip genome array to explore stress responses of CG (relative of barley), one of the most problematic weed species. Considering that almost half of the features on Barley1 GeneChip were called present once hybridized with CG RNA confirmed the applicability of barley microarray for CG stress response analysis, despite there is only partial homology of barley and CG genomes [5-7]. In addition, the CG homologs in barley genome involved in stress response was identified. Obtained information could contribute to both crop improvement and better weed management practice [22, 23]. Here we tested the hypothesis that the dehydration stress response of barley crown and the node of its wild extremely tolerant relative (couch grass) is different. We discuss mechanisms of acclimation to dehydration which play a crucial role in couch grass node, plant part critical for whole plant survival, similar to barley crown.

CG rhizomes are well adapted to regenerate following a period of moisture stress. The molecular basis of this adaptation was sought by subjecting rhizome segments to a range of simulated dehydration intensities, and documenting the induced changes to their transcriptome. The strategy was based on similar experiments designed to characterize the response to dehydration stress of the barley crown [16]. The resilience of the CG rhizomes was shown by the fact that, despite their partial dehydration, they retained a substantial degree of viability, according with the observations of Mikulka and Kneiflová [24]. The transcriptomic analysis revealed that the number of reprogrammed genes rose as the intensity of the dehydration was increased. The prominent role of ABA-responsive genes in dehydration stress response was evident in all the intervals of CG stress treatment together with the strong up-regulation of $\mathrm{ABA}$ synthesis genes - both NCED (AT1G78390.1) and zeaxanthin epoxidase (AT5G67030.1) were strong upregulated and this up-regulation was specific for couch grass in our experiment. Especially the very strong up-regulation of NCED might be the important step in CG dehydration response regarding its regulatory role in ABA biosynthesis [25].

Among the ABA-inducible genes up-regulated by the stress were a number encoding LEA proteins. The intensity of transcription of HVA1 (AT3G15670.1), a barley member of this group of proteins, has been shown to be positively correlated with drought tolerance not just in barley, but also in other plant species [26-31]. WSI18 (AT3G15670.1) is another LEA gene thought to be drought-responsive [32-34], while the LEA14-A (AT1G01470.1) protein possesses a level of sequence identity with a protein induced in the leaf and root of the resurrection plant Craterostigma plantagineum during desiccation and following the exogenous supply of $\mathrm{ABA}$, as well as in callus challenged with $\mathrm{NaCl}$ [35]. The 
Table 3 Genes stimulated or inhibited by dehydration within couch grass rhizomes selected for qRT-PCR analysis, sequences of the primers and amplification efficiencies

\begin{tabular}{|c|c|c|c|c|}
\hline$\overline{\mathrm{ID}^{\mathrm{a}}}$ & $\left.A G\right|^{b}$ & Name $^{c}$ & Primer sequence & Efficiency (\%) \\
\hline \multirow[t]{2}{*}{ Contig15047_at } & AT5G20730.2 & NPH4_F & atcctatcccctcaagaagtgcaaa & 93 \\
\hline & & $\mathrm{NPH} 4 \_\mathrm{R}$ & tggtcgtaacgaggcttccaagtat & \\
\hline \multirow[t]{2}{*}{ Contig1223_at } & AT3G53420.2 & PIP_F & agtacgtcctgagggcgagtg & 92 \\
\hline & & PIP_R & cacgatccgagccatatcacactgat & \\
\hline \multirow[t]{2}{*}{ Contig14720_s_at } & AT1G34260.1 & PI3PK_F & gagtttgtacttggcatcatcgact & 95 \\
\hline & & PI3PK_R & aaccgttaggaaatacttggecatg & \\
\hline \multirow[t]{2}{*}{ HVSMEf0022D18r2_s_at } & AT3G22600.1 & LTPG5_F & gatcgggttggcgcgcataca & 92 \\
\hline & & LTPG5_R & atgcatgtcacggtacaacaaatgga & \\
\hline \multirow[t]{2}{*}{ Contig10474_at } & AT1G80950.1 & PLGAC_F & gttgctctttcctgagggcac & 108 \\
\hline & & PLGAC_R & aaaatgactggttgtactggtgctc & \\
\hline \multirow[t]{2}{*}{ Contig3810_at } & AT1G09350.1 & WSI76_F & tacgtgcaagcacacggttgg & 97 \\
\hline & & WSI76_R & acgtttcagccatgcatacgtgtacg & \\
\hline \multirow[t]{2}{*}{ Contig14329_at } & AT1G04870.2 & PRMT10_F & ttgatgactccatctccgagagtaa & 94 \\
\hline & & PRMT10_R & atccatatccataagccggtgattc & \\
\hline \multirow[t]{2}{*}{ Contig10182_at } & AT1G15520.1 & $A B C_{-} F$ & tcagccctattgcatggacactcaa & 94 \\
\hline & & $A B C \_R$ & gctactacccacaggaagtcgtgat & \\
\hline \multirow[t]{2}{*}{ HT11N18r_s_at } & AT1G78390.1 & NCED_F & cttattaggcataggagatccccgg & 94 \\
\hline & & NCED_R & tgaagcaagtgtgagctaactgaat & \\
\hline \multirow[t]{2}{*}{ Contig1708_s_at } & AT4G01985.1 & DHN6_F & agcacaagaccggtggeatcct & 103 \\
\hline & & DHN6_R & tccttgttaccgecggggagct & \\
\hline \multirow[t]{2}{*}{ HW09B04u_at } & AT4G39670.1 & GLTP_F & cgttccatagctgggcaatccaga & 108 \\
\hline & & GLTP_R & acagagcaatcagtttcgttgagcc & \\
\hline \multirow[t]{2}{*}{ Contig2406_at } & AT3G15670.1 & WRAB1_F & ttgcctttgatttgatggtactcgtgt & 97 \\
\hline & & WRAB1_R & gtgccacctttcgactgtcctc & \\
\hline \multirow[t]{2}{*}{ Contig1718_s_at } & AT3G50980.1 & DHN9_F & aagacccgtgggatactgcatcgct & 96 \\
\hline & & DHN9_R & gtcgccatgtgctgctggttgtc & \\
\hline \multirow[t]{2}{*}{ Contig9547_at } & AT2G26830.1 & CEK4_F & ggcactcattcaggcaagggta & 95 \\
\hline & & CEK4_R & ctcctcagtgaagaaaggaagectt & \\
\hline \multirow[t]{2}{*}{ HVSMEf0019H18r2_s_at } & AT4G01470.1 & TIP1;3_F & atccatgcgtcatcgecatga & 96 \\
\hline & & TIP1;3_R & tgactgactcacacacagtttaccc & \\
\hline \multirow[t]{2}{*}{ Contig10112_at } & AT4G40060.1 & HB16_F & gatcctcggacagcgactcgagcg & 99 \\
\hline & & HB16_R & tgtccaggaacgacgcgccgaa & \\
\hline
\end{tabular}

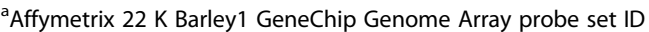

${ }^{\mathrm{b}} A$. thaliana locus identifier corresponding to individual IDs

${ }^{C} F$ forward, $R$ reverse, NPH4 Transcriptional factor B3 family protein, PIP plasma membrane intrinsic protein, aquaporin, $P I 3 P K$ phosphatidylinositol-3P 5-kinase, LTPG5 glycosylphosphatidylinositol-anchored lipid transfer protein 5, PGLAC phospholipid/glycerol acyltransferase, WSI76 galactinol synthase, PRMT10 histonearginine-N-methyltransferase, ABC ATP-binding cassette transporter, NCED 9-cis-epoxycarotenoid dioxygenase, DHN6 dehydrin DHN6, GLTP glycolipid transfer protein, WRAB1 ABA-inducible protein WRAB1, DHN9 dehydrin DHN9, CEK4 choline/ethanolamine kinase 4, TIP1;3 tonoplast intrinsic protein 1;3, HB16 homeobox protein 16

${ }^{\mathrm{d}}$ Amplification efficiency

suggestion is that the stress-induced up-regulation of these (and other) genes contributes to the high level dehydration tolerance shown by CG rhizomes.

Given that a common plant response to dehydration (and certain other abiotic stresses) is to accumulate sugars and other compatible solutes [36], it was not unexpected to find that genes encoding UDP-glucose 4- epimerase (UGE; AT4G23920.1), a putative trehalose-6phosphate phosphatase (AT4G12430.1), galactinol synthase (AT1G09350.1) and a putative raffinose synthase (AT5G40390.1) were all significantly up-regulated in the CG rhizomes by the simulated dehydration stress. The enzyme UDP-glucose 4-epimerase catalyzes the final step of galactose metabolism. In A. thaliana, genes 

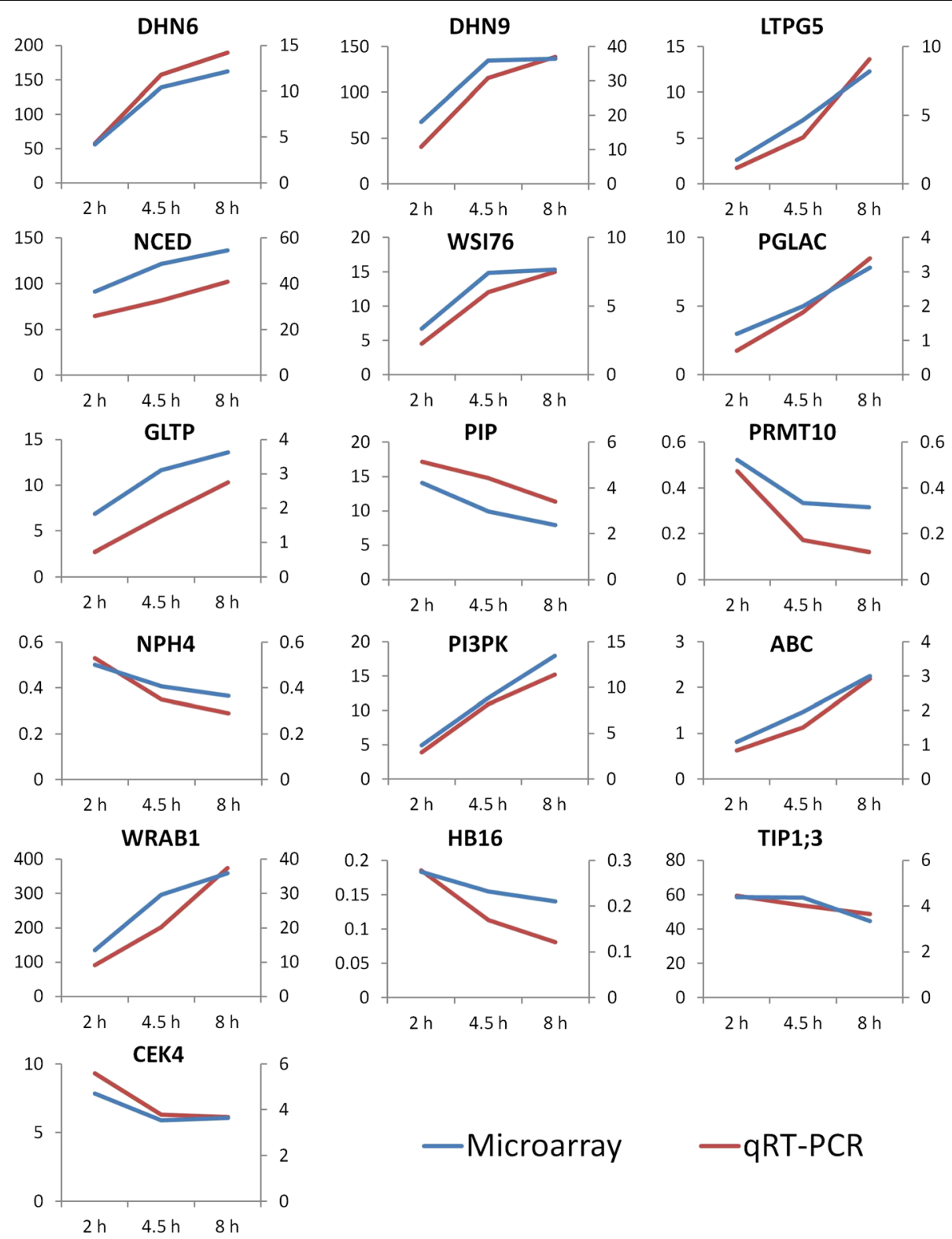

Fig. 7 Comparison of qRT-PCR and Microarray results for selected set of genes. Transcription fold changes between treated samples (2, 4.5 and $8 \mathrm{~h}$ of dehydration) and non-treated samples ( $0 \mathrm{~h}$ of dehydration) were calculated for both GRT-PCR and Microarray data. qRT-PCR values were obtained by delta Ct method and normalized to selected reference genes. Microarray data were normalized and Log2 fold change values were transformed to non-logarithmic scale for the comparison. Values of transcription fold change bellow 1 depicts the gene down-regulation under particular treatment, while the fold change above 1 shows the up-regulation of gene. $X$ axis depicts the duration of the stress. Primary $y$ axis (left side of the plot) shows the values of transcription fold changes from qRT-PCR (red line in the plot), while secondary y axis (right side of the plot) shows the transcription fold changes as meassured by microarray technique (blue line in the plot). NPH4 - Transcriptional factor B3 family protein, PIP - PIP aquaporin, PI3PK - phosphatidylinositol-3P 5-kinase -,LTPG5 - glycosylphosphatidylinositol-anchored lipid transfer protein 5, PGLAC phospholipid/glycerol acyltransferase, WSI76 - galactinol synthase, PRMT10 - histone-arginine-N-methyltransferase, ABC - ABC transporter, NCED - 9-cis-epoxycarotenoid dioxygenase, DHN6 - Dehydrin DHN6, GLTP - glycolipid transfer protein, WRAB1 - ABA-inducible protein WRAB1, DHN9 - dehydrin DHN9, CEK4 - choline/ethanolamine kinase 4, TIP1;3 - tonoplast intrinsic protein 1;3, HB16 - homeobox protein 16

encoding this protein appear to be induced by drought, low temperature and salinity stress [37], and some UGE isoforms have been shown to be involved in the stress response [38]. The rice homlog OsUGE-1 can be induced by various abiotic stress agents [39]. The implication is therefore that producing a high level of UGE activity in the CG rhizomes can represent an adaptation to dehydration stress. Trehalose-6-phosphate phosphatase (TPP) processes trehalose 6-phosphate to produce trehalose, an important disacharide in the 
context of acquiring drought tolerance: a positive correlation has been established between the abundance of TPP transcript and drought tolerance in rice [40, 41]. Both galactinol synthase and raffinose synthase are involved in the synthesis of the raffinose oligosacharides, which act as osmoprotectants: their beneficial effect for plants exposed to drought has been well documented [42-44]. Proline is probably the most well studied compatible solute. The over-accumulation of proline by transgenic rice plants over-expressing a gene encoding $\delta$-1-pyrroline-5-carboxylate synthase (AT2G39800.1) was correlated with the plants' improved capacity to withstand both moisture and salinity stress [45]. Similarly, transgenic tobacco plants constitutively expressing a homolog from Vigna aconitifolia produced more proline than wild type plants, resulting in a boost to both root growth and seed yield under conditions of drought stress [46]. The strong up-regulation of this gene in the CG rhizomes is thus consistent with proline accumulation being an aspect of the structure's adaptation to dehydration.

Genes encoding a number of proteins involved in stress signal transduction were also up-regulated in the CG rhizomes by the simulated dehydration stress treatments; one of these was a homolog of PKABA1 (AT4G33950.1). In non-stressed wheat seedlings, $P K A B A 1$ is transcribed at a very low level, but this changes dramatically when they are exposed to abiotic stress [47, 48]. Another example, protein phosphatase 2C (AT1G72770.3, AT4G28400.1, AT4G31750.1, AT1 G72770.3) is considered to be a negative regulator of ABA: the accumulation of transcripts occurs in response to moisture stress in barley $[49$, 50]. PI3PK (AT1G34260.1) is known to be up-regulated in barley roots exposed to prolonged salinity stress [51], while in A. thaliana $P I P 5 K$ is rapidly induced by exposure to drought, salinity and exogenous ABA [52].

The barley protein Blt 101.1 (AT2G38905.1), strongly up-regulated in CG, belongs to a gene family whose members are responsible for the maintenance of plasma membrane potential during a stress episode [53]. Its encoding gene is strongly transcribed in the vasculartransition zone of the barley crown [54], considered to be the part of the mature plant most sensitive to freezing damage. The protein has been described as freezing-, but not drought-responsive [55], although its response to dehydration in the crown has not been systematically studied as yet.

The up-regulation of genes encoding various transporters observed in the mild dehydration stress treatment suggested that a stimulation of transport activity may represent an early response to the stress. MIPs (major intrinsic proteins) enable a rapid and reversible alteration in water permeability [56]. Their regulation of water movement during a drought episode has been proposed by Chaumont and Tyermon [57], based on their expression at the apoplastic barrier in the root [58]. In a leaf of drought treated plant, MIPs participate in the regulation of stomatal movement [59], while in the root, plasma membrane intrinsic proteins (PIPs), a sub-class of the MIP family, are generally reduced in abundance, thereby helping to minimize water loss [60]. According to Lian et al. [61] PIPs are less abundant in the root of a drought sensitive rice cultivar than in a resistant one. The importance of PIPs for the recovery of $A$. thaliana from water-deficient conditions has been demonstrated by [62]. Both the CG node and the barley crown, while both being derived from the stem, are sub-surface structures. Their epidermis, unlike that of the root, is covered with a water-impervious cuticle and, unlike leaves, are not photosynthetically active. In addition, crowns and nodes are crucial for plant survival $[63,64]$, which lead us to the presumption that these parts of plant are preferentially protected. Three transporter genes behaved differently in the comparison between the CG rhizome and the barley crown. These encoded a PIP2A (AT3G53420.2), a VIT 1.1 (AT2G01770.1) and TIP1;3 (AT4G01470.1), and were each down-regulated in the barley tissue (both cultivars), but up-regulated in CG in response to dehydration stress. They may therefore represent a CG-specific stress adaptation. PIPs are believed to have dual ion and water permeability [65] and behave as a platform for recruitment of a wide range of transport activities [66]. TIPs are important players in mediation of water transport across tonoplast, which is important for osmotic adjustment during drought stress response [67]. E.g. it was shown, that the Thellungiella salsuginea tonoplast aquaporin TsTIP1;2 functions in protection against multiple abiotic stresses [68]. Increase in water absorption requires not only roots elongation, but also high water permeability in the tonoplast enabled by TIPs [69].

A significant group of DTGs was represented by genes encoding lipid transport proteins (LTPs): most of these were up-regulated by the stress, in some cases in both CG and barley. LTPs regulate vesicular trafficking, signal transduction and lipid metabolism [70]. Examples of these genes were LTPG5 encoding glycosylphosphatidylinositolanchored lipid protein transfer 5 (AT3G22600.1), involved in the accumulation of suberin and sporopolenin [71]; a gene encoding GLTP (AT4G39670.1); and a gene encoding a voltage-dependent L-type calcium channel subunit (AT5G16550.1). Some LTP-encoding genes associated with development were also strongly up-regulated: two examples were TED4 (AT3G18280.1), which participates in xylem development [72] and a homolog of an $A$. thaliana gene encoding PGLAC (AT1G80950.1), which is a component of the regulation of growth [73]. LTPs have 
been implicated in both freezing and drought tolerance $[74,75]$, and are also important transporters of lipids to the cuticle [69]. Some of the material targeted to the cuticle is transported within oleosomes, structures which are coated by oleosin-like proteins [76]. Their transport through the hydrophilic cell wall is facilitated by LTPs [77, 78]. A gene encoding oleosin (AT4G25140.1) was up-regulated in both the crown of barley cv. Tadmor and the CG rhizome subjected to dehydration stress. Unexpectedly, a gene encoding ABCG11 (AT1G17840. $1)$, a protein required for cutin transport to the extracellular matrix [79], was down-regulated in mildly stressed CG rhizomes, although this was reversed in the stronger stress treatments. Two other genes encoding ABC transporters (AT5G64940.1; AT4G04770. 1) were up-regulated in all of the treatments: one of these (AT5G64940.1) is involved not only in lipid synthesis [80], but also in cross talk between ABA and reactive oxygen species signaling [81]. A further five $\mathrm{ABC}$ transporter genes were up-regulated by the severe dehydration stress treatment (AT5G60740.1, AT4G39850. 2, AT5G60740.1, AT4G39850.1, AT1G15520.1).

Under the most severe level of dehydration stress tested, the transcription of several genes encoding products associated with development and translation were down-regulated, while genes encoding products involved in the synthesis of phenolic compounds behaved in the opposite manner. As shown by the ability of CG rhizomes to retain much of their viability even after being exposed to severe moisture stress, suggesting this processes are still reversible. The more drought tolerant barley cultivar shared some similarities with CG, implying that their response was to remain in the vegetative state and to inhibit root branching as will be explained in the following sentences. The down-regulation of PRMT10 (AT1G04870.2) and NPH4 (AT5G20730.2) is consistent with this conclusion and transcription of both these genes was verified by real-time PCR. A similar inhibition of root branching occurs in A. thaliana in response to ABA treatment, a partial surrogate for drought stress. [82] have shown that the drought tolerance of maize can be improved by reducing lateral root branching. Harris [83] have demonstrated how $\mathrm{ABA}$ is involved in the regulation of root architecture in plants exposed to various stress agents. The upregulation of a gene encoding a phosphatidyl serine synthase in CG was not mirrored in barley in our experiment. The translocation of phosphatidyl serine between organelles and its exposure to the cytosol have been suggested to be important for development [84]. Note that a gene encoding PI3PK (AT1G34260.1) was also strongly up-regulated in dehydration-treated CG rhizomes. Hirano et al. [19] have reported that in A. thaliana, mutations in this gene lead to an impairment of endomembrane homeostasis, resulting in a number of pleiotropic developmental abnormalities. Rapid ABA-induced stomatal closure requires the presence of phosphatidylinositol 3,5-bisphosphate, a product of phosphatidylinositol-3P 5-kinase [85]. A further strongly up-regulated gene in CG encoded 1deoxy-D-xylulose 5-phosphate reductoisomerase (AT5G62790.1), an enzyme participating in isoprenoid synthesis; the isoprenoids represent a diverse group of metabolites involved in photosynthesis, the regulation of growth and interactions with the environment [86]. The product of a gene encoding CEK4 (AT2G26830.1), which was up-regulated in CG but not in barley, catalyzes the initial steps of phospholipid synthesis [87].

\section{Conclusion}

Given that nearly half of the barley probe sets were informative for couch grass, accessing the transcriptome of a crop wild relative using a commercially available chip would appear to represent a simple means of identifying the set of genes associated with a particular process, such as in this case the dehydration tolerance of couch grass. Such information could be of interest not only in the context of improving the performance of a crop species, but also of devising strategies aimed at controlling the growth of weeds.

The results of this transcriptomic survey are consistent with ABA having a prominent role in the drought stress response, along with exerting an influence over development and lipid metabolism. Our results pointed out the important role of transporters and re-programming of the developmental process and root architecture mediated by ABA. The analyzed meristematic part (crown and node) is the main part of plant that had to survive in case of the whole plant survival. Its survival is probably (according to transcriptomic data) connected not only with altered root architecture suggesting altered water output, but also with consolidation of the lipidic barrier on the node surface and altered lipidic metabolism as well as altered activity of water channels and other transporters. These adaptations are according to transcriptomic data suggested to be greatly developed in the meristematic nodes of couch grass. The main results were confirmed via real-time PCR.

\section{Methods}

\section{Plant material and drought treatments}

CG rhizomes were collected from the field (trials were carried out in Prague-Ruzyně - local soil type Orthic Luvisol; average conditions of the field from the day of collection: $14.1{ }^{\circ} \mathrm{C}$; wind $8.3 \mathrm{~m} / \mathrm{s}$; rainfall $1.2 \mathrm{~mm}$ ), washed and cut into $2 \mathrm{~cm}$ segments, centered on a single node (the meristematic section of the segment). 
Non-treated segments were snap-frozen in liquid nitrogen and stored at $-80{ }^{\circ} \mathrm{C}$, and the remaining were subjected to a range of dehydration treatments, comprising exposure to either $2 \mathrm{~h}, 4.5 \mathrm{~h}, 8 \mathrm{~h}$ and $22 \mathrm{~h}$ at $28{ }^{\circ} \mathrm{C}$, chosen to simulate an episode of, respectively, mild, medium, severe and lethal dehydration. At the end of the treatment, the node was subjected to a series of physiological assays (see below), while the rest of the segment was snap-frozen and stored at $-80{ }^{\circ} \mathrm{C}$. The frozen material was used as a source of RNA, extracted using the TRIzol reagent (Invitrogen, Carlsbad, CA, USA), and purified using an RNeasy column in the presence of DNase (Qiagen, Hilden, Germany). The RNA's quality was assessed through both agarose gel electrophoresis and the use of an Agilent 2100 Bioanalyzer (Agilent Technologies, Santa Clara, CA, USA). RNA was extracted from three rhizome segments per treatment and each sample was represented by three independent replicates.

\section{Transcriptomic analysis}

The RNA samples were hybridized to an Affymetrix 22 K Barley1 GeneChip Genome Array [88]. Barley1 GeneChip Genome Array is designed as a matrix of 712*712 features (506944). There is 502,874 oligonucleotide probes located on the chip. Each probe has 25 bases in length. Sequence of each probe is based on the consensus sequence of selected barley genes. Probe sets corresponding to individual genes are represented by 11 probes $100 \%$ complementary to reference sequence (PM; perfect match probes) and by 11 probes complementary to reference sequence except for the middle base (MM; mismatch probes). Only probe sets serving as a control are represented by $20 \mathrm{PM}$ and $20 \mathrm{MM}$ probes. The array contains probes corresponding to 22,840 genes.

Standard controls provided by the supplier were included and B2 oligonucleotides were added to each hybridization cocktail. PolyA controls (lys, phe, thr, dap) and hybridization controls (BioB, BioC, BioD and Cre) were used to monitor labeling and hybridization. Opensource software included within the $\mathrm{R}$ statistical package [89] were used for the statistical analysis of the chip outputs. The microarray raw data were subjected to preprocessing analysis using functions provided with the Affy package library [90], with emphasis on boxplots, density plots and Bland-Altman plot modification (MVA plot). Subsequently, the RMA method [91] was implemented to achieve normalization and to eliminate background noise and processing artefacts. An iterative median polishing procedure was used to summarize the data and to generate a single expression value for each probe set. The MAS 5.0 algorithm within the R "Affy" library was used to associate a "present", "marginal" or "absent" call for each probe, and this output was used as an initial filter to ensure that only calls for which all three replicates were recorded as present in at least one sample were retained. Differentially transcribed genes (DTGs) were defined as those for which the difference in transcript abundance was at least two fold; these were identified using a linear model for microarray analysis provided within the LIMMA library package [92]. Pairwise analyses of treated vs. parallel non-treated samples were accomplished, applying a $P$ value threshold of 0.05 . A principal component analysis (PCA) was carried out using routines implemented in the Amap library package [93]. DTGs which were either specific to or shared between treatment were visualized using a Venn diagram [94]. The same tool enabled the identification of specificity/commonality between CG and barley. Clusters of genes sharing similar transcriptional patterns were identified for a set of DTGs common to all of the dehydrated CG rhizome segments. Over-represented functional gene categories within each cluster were determined using GO enrichment analysis (http://bioinfo.cau.edu.cn/agriGO/). DTG annotation was achieved using the Plexdb tool (www.plexdb.org). Consensus sequences of selected probes were subjected to BLAST search against Uniref90 (www.uniprot.org) using BlastX, applying an e value threshold of 1e-4. A. thaliana identifiers (AGIs) (corresponding to Affymetrix identification numbers) of all of the DTGs were acquired from www.harvest.ucr.edu.

\section{Two-step real-time reverse transcription PCR (qRT-PCR)}

RNA was diluted to $150 \mathrm{ng} \mu \mathrm{l}^{-1}$ of which a $2 \mu \mathrm{l}$ aliquot was used as template in a reverse transcription reaction carried out in a volume of $100 \mu \mathrm{l}$ using TaqMan Reverse Transcription Reagents (Applied Biosystems, Foster City, CA, USA), according to manufacturer's protocol. A $2 \mu \mathrm{l}$ aliquot of the reaction product was then taken as the template for a subsequent $20 \mu \mathrm{l}$ qRT-PCR containing 7.2 $\mu \mathrm{H} 2 \mathrm{O}, 10 \mu \mathrm{l}$ Power SYBR Green PCR Master Mix (Applied Biosystems, USA) and $200 \mathrm{nM}$ of each relevant primer. The amplification regime comprised a $10 \mathrm{~min}$ denaturation at $95{ }^{\circ} \mathrm{C}$, followed by 40 cycles of $95{ }^{\circ} \mathrm{C} /$ $15 \mathrm{~s}$ and $60{ }^{\circ} \mathrm{C} / 60 \mathrm{~s}$. The signal was recorded during the annealing phase of each cycle. Melting curves of PCR products were also recorded. The specificity of the amplicon was checked by electrophoresis through a $2 \%$ $w / v$ agarose gel and the melting curves were evaluated (data not shown). Three technical replicates of each biological sample (3 biological replicates of both treated and non-treated samples) were included.

We designed primer sequences for six candidate reference genes (RGs) used successfully in barley stress response studies before (Table 4). The suitability of each candidate reference gene was evaluated using three programs implemented within Microsoft Excel, namely GeNorm [95], NormFinder [96] and BestKeeper [97]. Because the ranking 
Table 4 Genes from which the primer sequences of candidate reference genes were derived, sequences of the primers and amplification efficiencies

\begin{tabular}{|c|c|c|c|c|}
\hline$I D^{a}$ & $\left.A G\right|^{b}$ & Name $^{c}$ & Primer sequence & Efficiency $(\%)^{d}$ \\
\hline \multirow[t]{2}{*}{ Contig1390_3_s_at } & AT5G09810.1 & ACT_F & tcactcagcactttccaacagatgt & 105 \\
\hline & & $A C T \_R$ & gactagatgataacagcagtggagc & \\
\hline \multirow[t]{2}{*}{ Contig2580_3_s_at } & AT1G69410.1 & IF5A_F & tttgggacccttgtgtttcctatgg & 95 \\
\hline & & IF5A_R & tttctggcatacagtttgcaccgtc & \\
\hline \multirow[t]{2}{*}{ Contig1008_x_at } & AT5G14670.1 & ADP-RF_F & tagttctctcgggatgtcgggggtc & 91 \\
\hline & & ADP-RF_R & gacaaaaatgagaccctgggtgttctga & \\
\hline \multirow[t]{2}{*}{ Contig21863_at } & & HSP90_R & ggacgctgtttattggctacgacga & 103 \\
\hline & & HSP90_F & tccatacacacagtcgggacgtatc & \\
\hline \multirow[t]{2}{*}{ Contig306_s_at } & AT5G45350.2 & SIGPRP_F & taccctggctcatctggtcacagtg & 90 \\
\hline & & SIGPRP_R & agagatcttgtgtgctccgtaagcg & \\
\hline \multirow[t]{2}{*}{ Contig149_at } & AT1G13440.1 & GAPDH_F & gggttcccactgtggatgtgtcagt & 91 \\
\hline & & GAPDH_R & ttccctcggaagcagecttgatagc & \\
\hline
\end{tabular}

${ }^{a}$ Affymetrix $22 \mathrm{~K}$ Barley1 GeneChip Genome Array probe set ID

${ }^{\mathrm{b}} A$. thaliana locus identifier corresponding to individual IDs

${ }^{c} F$ forward, $R$ reverse, ACT Actin, IF5A Translation elongation factor $5 \mathrm{~A}, A D P-R F$ ADP-ribosylation factor, HSP90 cytosolic heat shock protein 90 , SIGPRP similar to GPRP (proteins rich in glycine and proline), GAPDH glyceraldehyde-3-phosphate dehydrogenase

${ }^{\mathrm{d}}$ Amplification efficiency

of the RGs tested differed depending on which algorithm was used (see Additional file 13: Table S2); thus, we also used RefFinder (http://leonxie.esy.es/RefFinder/?type=reference\#), a web-based tool that integrates the outcomes of four different algorithms, namely GeNorm, NormFinder, BestKeeper and comparative Delta Ct method [98]. The genes are ranked according to the individual algorithms in RefFinder, and the geometric mean is calculated based on a particular weighting. The genes with the lowest value are considered the most stable. The final ranking of candidate reference genes according to GeNorm, NormFinder and BestKeeper as well as RefFinder is displayed in Additional file 13: Table S2.

To find out the optimal number of reference genes, we applied the pairwise variation (V) within GeNorm (see Additional file 14: Figure S1). The pairwise variation $V$ is based on the comparison between NFn (normalization factor) of the most stable control genes and $\mathrm{NF}_{\mathrm{n}+1}$, reflecting the effect of additional gene $(\mathrm{n}+$ 1) inclusion. The inclusion of additional RGs is recommended when the variation exceeds the 0.15 cut-off value. If the variation is below this limit, the inclusion of another gene is not required [95]. Therefore, we choose combination of two most stable reference genes (GAPDH, ADP-RF) suitable enough for normalization, since the V2/3 value $(0.100)$ was below the limit for additional gene inclusion.

The qRT-PCR efficiency for each target gene was calculated using qRT-PCR 10 -fold serially diluted cDNA in triplicate and the following formula: $E=\left(10^{-1 / S_{*}} 100\right)-100$ where $E$ is amplicon efficiency and $S$ is a slope of standard curve. Only sequences associated with the efficiency of $>90 \%$ were taken forward (Table 4).

Several genes stimulated/inhibited by dehydration within couch grass rhizomes were selected for qRT-PCR analysis (Table 3). Results were compared with those obtained from microarray to validate the data. Target cDNA sequences were derived from contig probe sequences within Affymetrix Barley1 GeneChip Genome Array. PCR primers were designed using FastPCR software (Primer design Ltd., Finland), and their specificity was verified by a BLAST search of the NetAff ${ }^{\mathrm{mat}}$ Analysis Center and NCBI databases.

\section{Calculation of normalized transcription of selected genes in qRT-PCR and comparison between qRT-PCR and microarray data}

Real time transcription values was calculated using delta $\mathrm{Ct}$ method. Relative transcript abundance was calculated using the formula: $Q=E^{\left.\overline{C t}_{0 h}-\overline{C t}_{\text {sample }}\right)}$ where $Q$ is a relative transcript abundance, Eis amplification efficiency of gene of interest (GOI), $\overline{C t}_{0 h}$ is a Cycle threshold average value in non-treated samples ( $0 \mathrm{~h}$ of dehydration) and $\overline{C t}_{\text {sample }}$ is cycle threshold average value in the specific treated sample. In the next step, the values of normalized transcription $\left(C G_{N O R M}\right)$ was generated using the formula: $C G_{N O R M}=\frac{Q_{C G}}{N F_{N}}$ where $Q$ is a relative transcript abundance of GOI in specific treated sample and $N F$ is a normalization factor $N F_{N}=\frac{1}{N} \sum_{i=1}^{N} Q_{R E F}$, representing the geometric mean of relative transcript abundances of 
selected reference genes ( $Q_{R E F}$ ) genes in individual treated samples. $N$ is a number of reference genes.

The differences in the gene transcription between treated and non-treated samples on the microarray generated by the LIMMA algorithm are $\log 2$ transformed. For their comparison with the real time the fold changes were transformed to non-logarithmic scale using the formula $2^{\log 2 F C}$.

\section{Physiological analyses}

The rhizome material surrounding the node was used to acquire key physiological parameters. These were: relative water content (RWC), calculated from the sample's fresh weight $(\mathrm{FW})$ and dry weight (DW), according to the formula $100 \mathrm{x}(\mathrm{FW}-\mathrm{DW}) / \mathrm{DW}$; electrolyte leakage, using a modified version of the protocol developed by Prášil and Zámečník [99], which produced the index $I_{t}$ derived from the formula $100 \times\left(R_{t}-R_{0}\right) /\left(R_{f}-R_{0}\right)$, where $R_{0}$ was the electric conductivity of the sample before treatment, $R_{\mathrm{f}}$ the conductivity of the sample after $22 \mathrm{~h}$ of dehydration treatment (lethal) and $R_{t}$ the relative conductivity expressed by the formula100 $\mathrm{x} \mathrm{L}_{\mathrm{t}} / \mathrm{L}_{\mathrm{tm}}$, where $L_{t}$ is the amount of electrolyte leakage from a treated sample and $\mathrm{L}_{\mathrm{tm}}$ is the maximal (total) leakage from treated sample (after killing the same sample by boiling). The degree of damage inflicted by the treatment on the rhizome was further quantified by examining the proportion of replanted treated rhizome segments to sprout when replanted in well-watered soil over a period of $7,14,21$ and 28 days.

\section{Additional files}

Additional file 1: Table S3. List of all genes within cluster 1. Average $\log 2$ transcriptions of individual probe sets under individual treatments are displayed as well as log2 FC of individual treatments against nontreated samples. Manufacturer annotation of individual IDs along with HarvEST annotation of individual AGls is included. (XLSX $41 \mathrm{~kb}$ )

Additional file 2: Table S4. List of all genes within cluster 2. Average $\log 2$ transcriptions of individual probe sets under individual treatments are displayed as well as $\log 2$ FC of individual treatments against nontreated samples. Manufacturer annotation of individual IDs along with HarvEST annotation of individual AGls is included. (XLSX $23 \mathrm{~kb}$ )

Additional file 3: Table S5. List of all genes within cluster 3. Average $\log 2$ transcriptions of individual probe sets under individual treatments are displayed as well as log2 FC of individual treatments against nontreated samples. Manufacturer annotation of individual IDs along with HarvEST annotation of individual AGls is included. (XLSX $22 \mathrm{~kb}$ )

Additional file 4: Table S6. List of all genes within cluster 4. Average $\log 2$ transcriptions of individual probe sets under individual treatments are displayed as well as log2 FC of individual treatments against nontreated samples. Manufacturer annotation of individual IDs along with HarvEST annotation of individual AGls is included. (XLSX $13 \mathrm{~kb}$ )

Additional file 5: Table S7. List of all genes within cluster 5. Average $\log 2$ transcriptions of individual probe sets under individual treatments are displayed as well as log2 FC of individual treatments against nontreated samples. Manufacturer annotation of individual IDs along with HarvEST annotation of individual AGls is included. (XLSX $15 \mathrm{~kb}$ )
Additional file 6: Table S8. List of all genes within cluster 6. Average $\log 2$ transcriptions of individual probe sets under individual treatments are displayed as well as log2 FC of individual treatments against nontreated samples. Manufacturer annotation of individual IDs along with HarvEST annotation of individual AGls is included. (XLSX $12 \mathrm{~kb}$ )

Additional file 7: Table S9. List of all genes within cluster 7. Average $\log 2$ transcriptions of individual probe sets under individual treatments are displayed as well as log2 FC of individual treatments against nontreated samples. Manufacturer annotation of individual IDs along with HarvEST annotation of individual AGls is included. (XLSX $9 \mathrm{~kb}$ )

Additional file 8: Table S10. List of all genes within cluster 8. Average $\log 2$ transcriptions of individual probe sets under individual treatments are displayed as well as log2 FC of individual treatments against nontreated samples. Manufacturer annotation of individual IDs along with HarvEST annotation of individual AGls is included. (XLSX $13 \mathrm{~kb}$ )

Additional file 9: Table S11. List of all genes within cluster 9. Average $\log 2$ transcriptions of individual probe sets under individual treatments are displayed as well as $\log 2 \mathrm{FC}$ of individual treatments against nontreated samples. Manufacturer annotation of individual IDs along with HarvEST annotation of individual AGls is included. (XLSX $10 \mathrm{~kb}$ )

Additional file $\mathbf{1 0}$ Table S12. List of all genes within cluster 10. Average $\log 2$ transcriptions of individual probe sets under individual treatments are displayed as well as log2 FC of individual treatments against non-treated samples. Manufacturer annotation of individual IDs along with HarvEST annotation of individual AGIs is included. (XLSX $9 \mathrm{~kb}$ )

Additional file 11: Table S13. List of all DTGs (810) specific to Couch Grass treated samples. Log2 FC of individual treatments against nontreated samples are displayed along with. Manufacturer annotation of individual IDs and HarvEST annotation of individual AGIs. (XLSX $122 \mathrm{~kb}$ )

Additional file 12: Table S1. Comparison of GRT-PCR and Microarray results for selected set of genes. Comparison of qRT-PCR and Microarray results for selected set of genes. Transcription fold changes between treated samples $(2,4.5$ and $8 \mathrm{~h}$ of dehydration) and non-treated samples ( $0 \mathrm{~h}$ of dehydration) were calculated for both QRT-PCR and Microarray data. GRT-PCR values were obtained by delta Ct method and normalized to selected reference genes. Microarray data were normalized and Log2 fold change values were transformed to non-logarithmic scale for the comparison. Values of transcription fold change bellow 1 depicts the gene down-regulation under particular treatment, while the fold changes above 1 shows the up-regulation of gene under particular treatment. NPH4 - Transcriptional factor B3 family protein, PIP - PIP aquaporin, PI3PK - phosphatidylinositol-3P 5-kinase -,LTPG5 - glycosylphosphatidylinositolanchored lipid transfer protein 5, PGLAC - phospholipid/glycerol acyltransferase, WSI76 - galactinol synthase, PRMT10 - histone-arginine-Nmethyltransferase, ABC - ABC transporter, NCED - 9-cis-epoxycarotenoid dioxygenase, DHN6 - Dehydrin DHN6, GLTP - glycolipid transfer protein, WRAB1 - ABA-inducible protein WRAB1, DHN9 - dehydrin DHN9, CEK4 choline/ethanolamine kinase 4, TIP1;3 - tonoplast intrinsic protein 1;3, HB16 - homeobox protein 16. (XLSX $12 \mathrm{~kb})$

Additional file 13: Table S2. Ranking of candidate reference genes according to used algorithms (GeNorm, NormFinder, BestKeeper and RefFinder). (XLSX $9 \mathrm{~kb}$ )

Additional file 14: Figure S1. Determination of the optimal number of reference genes for normalization using GeNorm Pairwise variation. The inclusion of additional RGs is recommended when the variation exceeds the 0.15 cut-off value, reppresented by the blue line within the plot. Since this is not the case and the value for V2/3 is bellow the limit, combination of two most stable reference genes was used for the normalization of $\mathrm{GOI}$. (JPG $160 \mathrm{~kb})$

\section{Abbreviations}

ABA: Abscisic acid; ABC transporter: ATP-binding cassette transporter: CEK4: Choline/ethanolamine kinase 4; CG: Couch grass; $C_{\text {norm: }}$ values of normalized transcription; DHN: Dehydrin; DM: Dry matter; DTGs: Differentially transcribed genes; DW: Dry weight; FW: Fresh weight; GLTP: Glycolipid transfer protein; HB16: Homeobox protein 16; LEA: Late embryogenesis abundant proteins; LHCII: Light-harvesting complex II;

LTPG5: Glycosylphosphatidylinositol-anchored lipid transfer protein 5; 
LTPS: Lipid transport proteins; NCED: 9-cis-epoxycarotenoid dioxygenase; NPH4: Transcriptional factor B3 family protein; PCA: Principal component analysis; PGLAC: Phospholipid/glycerol acyltransferase; PI3PK: Phosphatidylinositol-3P 5-kinase; PIP: Plasma membrane intrinsic protein, aquaporin; PRMT10: Histone-arginine-N-methyltransferase; PSII: Photosystem II; qRT-PCR: real-time PCR; RWC: Relative water content; TIP: Tonoplast intrinsic protein; VIT: Vacuolar iron transporter; WRAB1: ABAinducible protein WRAB1; WSI76: Galactinol synthase

\section{Acknowledgements}

Authors are grateful for the access to the computing and storage facilities provided by the National Grid Infrastructures MetaCentrum and CERIT-CS (LM2010005 and CZ.1.05/3.2.00/08.0144), which were very helpful in the data mining process. Special thanks belong to MSc Martin Grospietsch and Dr. Jiří Zámečník for experimental support with the plant material and physiological meassurements.

\section{Funding}

Authors highly appreciate the financial support from Specific University Research (MSMT No. 20/2015), the Ministry of Agriculture (RO0417), the National Agency for Agricultural Research (No. QH81287 and QJ1310055) and the project LO1417 of Czech ministry of Education Youth and Sports. The funders had no role in the study design, data collection and analysis, or preparation of the manuscript.

\section{Availability of data and materials}

The raw microarray data are available at the NCBI Gene Expression Omnibus with the accession number GSE112428.

\section{Authors' contributions}

All authors contributed equally to this work. AJ, LK, and JO suggested the study design, participated in data evaluation and wrote the text. PS and VS have done bioinformatics analysis, data comparison and data evaluation and wrote the text. All authors read and approved the final manuscript.

\section{Ethics approval and consent to participate}

Couch grass rhizomes used in this study were collected from the field of Crop Research Institute in Prague. No field permissions were necessary to collect the plant samples in this study and no specimens have been deposited as vouchers. The authors declared that experimental research works on the plants described in this paper comply with institutional, national and international guidelines.

\section{Competing interests}

The authors declare that the research was conducted in the absence of any commercial or financial relationships that could be construed as a potential conflict of interest.

\section{Publisher's Note}

Springer Nature remains neutral with regard to jurisdictional claims in published maps and institutional affiliations.

\section{Author details}

${ }^{1}$ Faculty of Science, Charles University, Prague, Czech Republic. ${ }^{2}$ Division of Crop Genetics and Breeding, Crop Research Institute, Prague, Czech Republic ${ }^{3}$ Factulty of Food and Biochemical Technology, University of Chemistry and Technology, Prague, Czech Republic.

\section{Received: 27 October 2017 Accepted: 18 April 2018} Published online: 02 May 2018

\section{References}

1. Beddington J, Asaduzzaman M, Fernandez A, Clark M, Guillou M, Jahn M, et al. Achieving food security in the face of climate change: summary for policy makers from the commission on sustainable agriculture and climate change. Copenhagen: CGIAR Research Program on Climate Change; 2011.

2. Devendra C. Climate change threats and effects: challenges for agriculture and food security. Kuala Lumpur: Academy of Sciences Malaysia; 2012

3. Field $\mathrm{CB}$, editor. Managing the risks of extreme events and disasters to advance climate change adaptation: special report of the intergovernmental panel on climate change. Cambridge: Cambridge University Press; 2012.
4. Reidy ME, Swanton CJ. Quackgrass. In OMAF factsheet. Ministry of Agriculture, Food and Rural Affairs. 1993. http://www.omafra.gov.on.ca/ english/crops/facts/quackgrass.htm. Accesed 1 June 1993.

5. Fahleson J, Okori P, Åkerblom-Espeby L, Dixelius C. Genetic variability and genomic divergence of Elymus repens and related species. Plant Syst Evol. 2008:271(3-4):143-56.

6. Mahelka V. On the origin and hybridization of polyploid wheatgrasses - on the trail of cryptic progenitors. Živa. 2013;61(4):149-53.

7. Mason-Gamer RJ. Phylogeny of a genomically diverse group of Elymus (Poaceae) allopolyploids reveals multiple levels of reticulation. PLoS One. 2013:8(11):e78449.

8. Zhang T, Zhao X, Huang L, Liu X, Zong Y, Zhu L, et al. Tissue-specific transcriptomic profiling of sorghum propinquum using a rice genome array. PLoS One. 2013;8(3):e60202.

9. Horvath DP, Schaffer R, West M, Wisman E. Arabidopsis microarrays identify conserved and differentially expressed genes involved in shoot growth and development from distantly related plant species. Plant J. 2003;34(1):125-34

10. Taji T, Seki M, Satou M, Sakurai T, Kobayashi M, Ishiyama K, et al. Comparative genomics in salt tolerance between Arabidopsis and Arabidopsis-related halophyte salt cress using Arabidopsis microarray. Plant Physiol. 2004;135(3):1697-709.

11. Weber M, Harada E, Vess C, Roepenack-Lahaye EV, Clemens S. Comparative microarray analysis of Arabidopsis thaliana and Arabidopsis halleri roots identifies nicotianamine synthase, a ZIP transporter and other genes as potential metal hyperaccumulation factors. Plant J. 2004;37(2):269-81.

12. Yang SS, Valdés-López $O$, Xu WW, Bucciarelli B, Gronwald JW, Hernández G, et al. Transcript profiling of common bean (Phaseolus vulgaris L.) using the GeneChip ${ }^{\oplus}$ soybean genome Array: optimizing analysis by masking biased probes. BMBMC Plant Biol. 2010;10(1):85

13. Bagnaresi $P$, Moschella A, Beretta O, Vitulli F, Ranalli P, Perata P. Heterologous microarray experiments allow the identification of the early events associated with potato tuber cold sweetening. BMC Genomics. 2008;9(1):176

14. Moore S, Payton P, Wright M, Tanksley S, Giovannoni J. Utilization of tomato microarrays for comparative gene expression analysis in the Solanaceae. J Exp Bot. 2005:56(421):2885-95.

15. Ponce-Valadez M, Fellman SM, Giovannoni J, Gan SS, Watkins CB. Differential fruit gene expression in two strawberry cultivars in response to elevated CO 2 during storage revealed by a heterologous fruit microarray approach. Postharvest Biol Tec. 2009;51(2):131-40.

16. Svoboda P, Janská A, Spiwok V, Prášil IT, Kosová K, Vítámvás P, Ovesná J. Global scale transcriptional profiling of two contrasting barley genotypes exposed to moderate drought conditions: contribution of leaves and crowns to water shortage coping strategies. Front Plant Sci. 2016;7:1958.

17. Kosová K, Vítámvás P, Prášil IT. Wheat and barley dehydrins under cold, drought, and salinity-what can LEA-II proteins tell us about plant stress response? Front Plant Sci. 2014;5:343

18. Baduel P, Arnold B, Weisman CM, Hunter B, Bomblies K. Habitat-associated life history and stress-tolerance variation in Arabidopsis arenosa. Plant Physiol. 2016:171(1):437-51.

19. Hirano T, Matsuzawa T, Takegawa K, Sato MH. Loss-of-function and gain-offunction mutations in FAB1A/B impair endomembrane homeostasis, conferring pleiotropic developmental abnormalities in Arabidopsis. Plant Physiol. $2011 ; 155(2): 797-807$.

20. Stührwohldt N, Dahlke Rl, Steffens B, Johnson A, Sauter M. Phytosulfokine-a controls hypocotyl length and cell expansion in Arabidopsis thaliana through phytosulfokine receptor 1. PLoS One. 2011;6(6):e21054.

21. Chen YE, Liu WJ, Su YQ, Cui JM, Zhang ZW, Yuan M, et al. Different response of photosystem $\|$ to short and long-term drought stress in Arabidopsis thaliana. Physiol Plantarum. 2016;158(2):225-35.

22. Horvath D. Genomics for weed science. Curr Genomics. 2010:11(1):47-51.

23. Horvath D. Recent genomic advances for weed science. In: Ch N, editor. Advances in genome science: keeping up with genome sequence and expression: Sharjah: Bentham Science Publishers; 2014. p. 127-42

24. Mikulka J, Kneifelová M. Vegetative reproduction of Cirsium arvense (I.) scop. Sonchus arvensis I., Stachys palustris I., Polygonum amphibium I. and Elytrigia repens (I.) desv. AcActa Herb. 2004;13(1):137-78. 
25. Qin X, Zeevaart JA. The 9-cis-epoxycarotenoid cleavage reaction is the key regulatory step of abscisic acid biosynthesis in water-stressed bean. Proc Nat Acad Sci USA. 1999;96(26):15354-61.

26. Rohila JS, Jain RK, Wu R. Genetic improvement of basmati rice for salt and drought tolerance by regulated expression of a barley Hva1 cDNA. Plant Sci. 2002;163(3):525-32.

27. Bahieldin A, Mahfouz HT, Eissa HF, Saleh OM, Ramadan AM, Ahmed IA, et al. Field evaluation of transgenic wheat plants stably expressing the HVA1 gene for drought tolerance. Physiol Plantarum. 2005;123(4):421-7.

28. Fu D, Huang B, Xiao Y, Muthukrishnan S, Liang GH. Overexpression of barley hval gene in creeping bentgrass for improving drought tolerance. Plant Cell Rep. 2007;26(4):467-77.

29. Checker VG, Chhibbar AK, Khurana P. Stress-inducible expression of barley Hva1 gene in transgenic mulberry displays enhanced tolerance against drought, salinity and cold stress. Transgenic Res. 2012;21(5):939-57.

30. Lal S, Gulyani V, Khurana P. Overexpression of HVA1 gene from barley generates tolerance to salinity and water stress in transgenic mulberry (Morus indica). Transgenic Res. 2008;17(4):651.

31. Nguyen TX, Sticklen M. Barley HVA1 gene confers drought and salt tolerance in transgenic maize (Zea mays L.). Adv Crop Sci Tech. 2013;1(105):2.

32. Takahashi $R$, Joshee $N$, Kitagawa $Y$. Induction of chilling resistance by water stress, and cDNA sequence analysis and expression of water stressregulated genes in rice. Plant Mol Biol. 1994;26(1):339-52.

33. Joshee $\mathrm{N}$, Kisaka H, Kitagawa $\mathrm{Y}$. Isolation and characterization of a water stressspecific genomic gene, pwsi 18, from rice. Plant Cell Physiol. 1998;39(1):64-72.

34. Shobbar ZS, Oane R, Gamuyao R, De Palma J, Malboobi MA, Karimzadeh G, et al. Abscisic acid regulates gene expression in cortical fiber cells and silica cells of rice shoots. New Phytol. 2008;178(1):68-79.

35. Piatkowski D, Schneider K, Salamini F, Bartels D. Characterization of five abscisic acid-responsive cDNA clones isolated from the desiccation-tolerant plant Craterostigma plantagineum and their relationship to other waterstress genes. Plant Physiol. 1990;94(4):1682-8.

36. Hare PD, Cress WA, Van Staden J. Dissecting the roles of osmolyte accumulation during stress. Plant Cell Environ. 1998;21(6):535-53.

37. Seki M, Narusaka M, Ishida J, Nanjo T, Fujita M, Oono $Y$, et al. Monitoring the expression profiles of 7000 Arabidopsis genes under drought, cold and high-salinity stresses using a full-length cDNA microarray. Plant J. 2002;31(3):279-92.

38. Rösti J, Barton CJ, Albrecht S, Dupree P, Pauly M, Findlay K, et al. UDPglucose 4-epimerase isoforms UGE2 and UGE4 cooperate in providing UDPgalactose for cell wall biosynthesis and growth of Arabidopsis thaliana. Plant Cell. 2007;19(5):1565-79.

39. Rabbani MA, Maruyama $K$, Abe H, Khan MA, Katsura $K$, Ito $Y$, et al. Monitoring expression profiles of rice genes under cold, drought, and highsalinity stresses and abscisic acid application using cDNA microarray and RNA gel-blot analyses. Plant Physiol. 2003;133(4):1755-67.

40. Ge LF, Chao DY, Shi M, Zhu MZ, Gao JP, Lin HX. Overexpression of the trehalose6-phosphate phosphatase gene OsTPP1 confers stress tolerance in rice and results in the activation of stress responsive genes. Planta. 2008;228(1):191-201.

41. Jang IC, Oh SJ, Seo JS, Choi WB, Song SI, Kim CH, et al. Expression of a bifunctional fusion of the Escherichia coli genes for trehalose-6-phosphate synthase and trehalose-6-phosphate phosphatase in transgenic rice plants increases trehalose accumulation and abiotic stress tolerance without stunting growth. Plant Physiol. 2003;131(2):516-24.

42. Valliyodan B, Nguyen HT. Understanding regulatory networks and engineering for enhanced drought tolerance in plants. Curr Opin Plant Biol. 2006;9(2):189-95.

43. Taji T, Ohsumi $C_{\text {, luchi }}$, Seki M, Kasuga M, Kobayashi M, et al. Important roles of drought-and cold-inducible genes for galactinol synthase in stress tolerance in Arabidopsis thaliana. Plant J. 2002;29(4):417-26.

44. Nishizawa A, Yabuta Y, Shigeoka S. Galactinol and raffinose constitute a novel function to protect plants from oxidative damage. Plant Physiol. 2008; 147(3):1251-63.

45. Zhu B, Su J, Chang M, Verma DPS, Fan YL, Wu R. Overexpression of a $\Delta$ 1pyrroline-5-carboxylate synthetase gene and analysis of tolerance to waterand salt-stress in transgenic rice. Plant Sci. 1998;139(1):41-8.

46. Kishor PK, Hong Z, Miao GH, Hu CAA, Verma DPS. Overexpression of [delta]pyrroline-5-carboxylate synthetase increases proline production and confers osmotolerance in transgenic plants. Plant Physiol. 1995;108(4):1387-94.

47. Anderberg RJ, Walker-Simmons MK. Isolation of a wheat CDNA clone for an abscisic acid-inducible transcript with homology to protein kinases. Proc Natl Acad Sci U S A. 1992;89(21):10183-7.
48. Holappa LD, Walker-Simmons MK. The wheat abscisic acid-responsive protein kinase mRNA, PKABA1, is up-regulated by dehydration, cold temperature, and osmotic stress. Plant Physiol. 1995;108(3):1203-10.

49. Ozturk ZN, Talamé V, Deyholos M, Michalowski CB, Galbraith DW, Gozukirmizi N, et al. Monitoring large-scale changes in transcript abundance in drought-and salt-stressed barley. Plant Mol Biol. 2002;48(5-6):551-73.

50. Guo P, Baum M, Grando S, Ceccarelli S, Bai G, Li R, et al. Differentially expressed genes between drought-tolerant and drought-sensitive barley genotypes in response to drought stress during the reproductive stage. J Exp Bot. 2009;60(12):3531-44.

51. Ueda A, Shi W, Nakamura T, Takabe T. Analysis of salt-inducible genes in barley roots by differential display. J P Res. 2002;115(2):0119-30.

52. Mikami K, Katagiri T, luchi S, Yamaguchi-Shinozaki K, Shinozaki K. A gene encoding phosphatidylinositol-4-phosphate 5-kinase is induced by water stress and abscisic acid in Arabidopsis thaliana. Plant J. 1998;15(4):563-8.

53. Navarre C, Goffeau A. Membrane hyperpolarization and salt sensitivity induced by deletion of PMP3, a highly conserved small protein of yeast plasma membrane. EMBO J. 2000;19(11):2515-24.

54. Pearce RS, Houlston CE, Atherton KM, Rixon JE, Harrison P, Hughes MA, et al. Localization of expression of three cold-induced genes, blt101, blt4. 9, and blt14, in different tissues of the crown and developing leaves of coldacclimated cultivated barley. PIPlant Physiol. 1998;117(3):787-95.

55. Goddard NJ, Dunn MA, Zhang L, White AJ, Jack PL, Hughes MA. Molecular analysis and spatial expression pattern of a low-temperature-specific barley gene, blt101. Plant Mol Biol. 1993;23(4):871-9.

56. Aroca R, Porcel R, Ruiz-Lozano JM. Regulation of root water uptake under abiotic stress conditions. J ExpBot. 2012;63(1):43-57.

57. Chaumont F, Tyerman SD. Aquaporins: highly regulated channels controlling plant water relations. Plant Physiol. 2014;164(4):1600-18.

58. Gambetta GA, Fei J, Rost TL, Knipfer T, Matthews MA, Shackel KA, et al. Water uptake along the length of grapevine fine roots: developmental anatomy, tissue-specific aquaporin expression, and pathways of water transport. Plant Physiol. 2013;163(3):1254-65

59. Heinen RB, Ye Q, Chaumont F. Role of aquaporins in leaf physiology. J Exp Bot. 2009;60(11):2971-85

60. Moshelion M, Halperin O, Wallach R, Oren R, Way DA. Role of aquaporins in determining transpiration and photosynthesis in waterstressed plants: crop water-use efficiency, growth and yield. Plant Cell Environ. 2014;38(9):1785-93.

61. Lian HL, Yu X, Lane D, Sun WN, Tang ZC, Su WA. Upland rice and lowland rice exhibited different PIP expression under water deficit and ABA treatment. Cell Res. 2006;16(7):651.

62. Martre P, Morillon R, Barrieu F, North GB, Nobel PS, Chrispeels MJ. Plasma membrane aquaporins play a significant role during recovery from water deficit. Plant Physiol. 2002;130(4):2101-10.

63. Olien CR. Freezing stresses and survival. Ann Rev Plant Physio. 1967;18(1): 387-408.

64. Winfield MO, Lu C, Wilson ID, Coghill JA, Edwards KJ. Plant responses to cold: transcriptome analysis of wheat. Plant Biotech J. 2010;8(7):749-71.

65. Byrt CS, Zhao M, Kourghi M, Bose J, Henderson SW, Qiu J, et al. Non selective cation channel activity of aquaporin AtPIP2;1 regulated by $\mathrm{Ca} 2+$ and pH. Plant Cell Environ. 2017;40(6):802-15.

66. Bellati J, Champeyroux C, Hem S, Rofidal V, Krouk G, Maurel C, Santoni V. Novel aquaporin regulatory mechanisms revealed by interactomics. Mol Cell Proteomics. 2016:15(11):3473-87.

67. Wudick MM, Luu DT, Maurel C. A look inside: localization patterns and functions of intracellular plant aquaporins. New Phytol. 2009;184(2):289-302.

68. Wang LL, Chen AP, Zhong NQ, Liu N, Wu XM, Wang F, et al. The Thellungiella salsuginea tonoplast aquaporin TSTIP1;2 functions in protection against multiple abiotic stresses. Plant Cell Physiol. 2014;55(1):148-61.

69. Peng Y, Lin W, Cai W, Arora R. Overexpression of a Panax ginseng tonoplast aquaporin alters salt tolerance, drought tolerance and cold acclimation ability in transgenic Arabidopsis plants. Planta. 2007;226(3):729-40.

70. Lev S. Nonvesicular lipid transfer from the endoplasmic reticulum. CSH Perspect Biol. 2012;4(10):a013300.

71. Edstam MM, Blomqvist K, Eklöf A, Wennergren U, Edqvist J. Coexpression patterns indicate that GPI-anchored non-specific lipid transfer proteins are involved in accumulation of cuticular wax, suberin and sporopollenin. Plant Mol Biol. 2013;83(6):625-49.

72. Endo $\mathrm{S}$, Iwamoto K, Fukuda $\mathrm{H}$. Overexpression and cosuppression of xylem-related genes in an early xylem differentiation stage-specific 
manner by the AtTED4 promoter. Plant Biotechnol J. 2017; https://doi. org/10.1111/pbi.12784.

73. Jasieniecka-Gazarkiewicz K, Lager I, Carlsson A, Gutbrod K, Peisker H, Dörmann P, et al. Acyl-CoA: lysophosphatidylethanolamine acyltransferase activity affects growth. Plant Physiol. 2017; https://doi. org/10.1104/pp.17.00391.

74. Guo L, Yang H, Zhang $X$, Yang S. Lipid transfer protein 3 as a target of MYB96 mediates freezing and drought stress in Arabidopsis. J Exp Bot. 2013; 64(6):1755-67.

75. Janská A, Aprile A, Cattivelli L, Zámečník J, de Bellis L, Ovesná J. The upregulation of elongation factors in the barley leaf and the down-regulation of nucleosome assembly genes in the crown are both associated with the expression of frost tolerance. Funct Integr Genomic. 2014;14(3):493-506.

76. Jarzyniak KM, Jasiński M. Membrane transporters and drought resistance-a complex issue. Front Plant Sci. 2014:5:687.

77. Kim H, Lee SB, Kim HJ, Min MK, Hwang I, Suh MC. Characterization of glycosylphosphatidylinositol-anchored lipid transfer protein 2 (LTPG2) and overlapping function between LTPG/LTPG1 and LTPG2 in cuticular wax export or accumulation in Arabidopsis thaliana. Plant Cell Physiol. 2012:53(8):1391-403.

78. DeBono A, Yeats TH, Rose JK, Bird D, Jetter $R$, Kunst $L$, et al. Arabidopsis $L T P G$ is a glycosylphosphatidylinositol-anchored lipid transfer protein required for export of lipids to the plant surface. Plant Cell. 2009;21(4):1230-8.

79. McFarlane HE, Shin JJ, Bird DA, Samuels AL. Arabidopsis ABCG transporters, which are required for export of diverse cuticular lipids, dimerize in different combinations. Plant Cell. 2010;22(9):3066-75.

80. Manara A, DalCorso G, Guzzo F, Furini A. Loss of the atypical kinases $A B C 1 K 7$ and $A B C 1 K 8$ changes the lipid composition of the chloroplast membrane. Plant Cell Physiol. 2015;56(6):1193-204.

81. Manara A, DalCorso G, Furini A. The role of the atypical kinases ABC1K7 and ABC1K8 in abscisic acid responses. Front Plant Sci. 2016;7:366.

82. Zhang Y, Behrens IV, Zimmermann R, Ludwig Y, Hey S, Hochholdinger F. LATERAL ROOT PRIMORDIA 1 of maize acts as a transcriptional activator in auxin signalling downstream of the aux/IAA gene rootless with undetectable meristem 1. J Exp Bot. 2015;66(13):3855-63.

83. Harris JM. Abscisic acid: hidden architect of root system structure. Plants. 2015:4(3):548-72.

84. Yamaoka Y, Fujiki Y, Lee Y, Nishida I. Subcellular localization of phosphatydilserine in A. thaliana. 21st internetation conference on Arabidopsis research; 2010

85. Bak G, Lee EJ, Lee Y, Kato M, Segami S, Sze H, et al. Rapid structural changes and acidification of guard cell vacuoles during stomatal closure require phosphatidylinositol 3, 5-bisphosphate. Plant Cell. 2013;25(6):2202-16.

86. Perello C, Llamas E, Burlat V, Ortiz-Alcaide M, Phillips MA, Pulido P, et al. Differential subplastidial localization and turnover of enzymes involved in isoprenoid biosynthesis in chloroplasts. PLoS One. 2016;11(2):e0150539.

87. Lin YC, Liu YC, Nakamura Y. The choline/ethanolamine kinase family in Arabidopsis: essential role of CEK4 in phospholipid biosynthesis and embryo development. Plant Cell. 2015;27(5):1497-511.

88. Close TJ, Wanamaker SI, Caldo RA, Turner SM, Ashlock DA, Dickerson JA, et al. A new resource for cereal genomics: 22K barley GeneChip comes of age. Plant Physiol. 2004;134(3):960-8.

89. R Core Team. R: a language and environment for statistical computing; 2015.

90. Gautier L, Cope L, Bolstad BM, Irizarry RA. affy—analysis of Affymetrix GeneChip data at the probe level. Bioinformatics. 2004;20(3):307-15.

91. Irizarry RA, Hobbs B, Collin F, Beazer-Barclay YD, Antonellis K, Scherf U, et al. Exploration, normalization, and summaries of high density oligonucleotide array probe level data. Biostatistics. 2003;4(2):249-64.

92. Smyth GK. Linear models and empirical bayes methods for assessing differential expression in microarray experiments. Stat Appl Genet Mo B. 2004:3(1):1-25.

93. Lucas A. Amap: another multidimensional analysis package; 2014

94. Chen H. VennDiagram: generate high-resolution Venn and Euler plots; 2013.

95. Vandesompele J, De Preter K, Pattyn F, Poppe B, Van Roy N, De Paepe A, et al. Accurate normalization of real-time quantitative RT-PCR data by geometric averaging of multiple internal control genes. Genome Biol. 2002; 3(7):research0034-1.

96. Andersen $\mathrm{CL}$, Jensen $\mathrm{JL}$, Ørntoft TF. Normalization of real-time quantitative reverse transcription-PCR data: a model-based variance estimation approach to identify genes suited for normalization, applied to bladder and colon cancer data sets. Cancer Res. 2004;64(15):5245-50.
97. Pfaffl MW, Tichopad A, Prgomet C, Neuvians TP. Determination of stable housekeeping genes, differentially regulated target genes and sample integrity: BestKeeper-excel-based tool using pair-wise correlations. Biotechnol Lett. 2004;26(6):509-15.

98. Silver N, Best S, Jiang J, Thein SL. Selection of housekeeping genes for gene expression studies in human reticulocytes using real-time PCR. BMC Mol Biol. 2006;7(1):33.

99. Prášil I, Zámečník J. The use of a conductivity measurement method for assessing freezing injury: I. Influence of leakage time, segment number, size and shape in a sample on evaluation of the degree of injury. Environ Exp Botany. 1998;40(1):1-10

\section{Ready to submit your research? Choose BMC and benefit from:}

- fast, convenient online submission

- thorough peer review by experienced researchers in your field

- rapid publication on acceptance

- support for research data, including large and complex data types

- gold Open Access which fosters wider collaboration and increased citations

- maximum visibility for your research: over $100 \mathrm{M}$ website views per year

At BMC, research is always in progress.

Learn more biomedcentral.com/submissions 